\title{
GCU
}

Glasgow Caledonian

University

University for the Common Good

\section{A narrative review of communication accessibility for people with aphasia and implications for multi-disciplinary goal setting after stroke}

Brown, Sophie Eleanor; Brady, Marian C.; Worrall, Linda; Scobbie, Lesley

Published in:

Aphasiology

DOI:

10.1080/02687038.2020.1759269

Publication date:

2021

Document Version

Author accepted manuscript

Link to publication in ResearchOnline

Citation for published version (Harvard):

Brown, SE, Brady, MC, Worrall, L \& Scobbie, L 2021, 'A narrative review of communication accessibility for people with aphasia and implications for multi-disciplinary goal setting after stroke', Aphasiology, vol. 35, no. 1, pp. 1-32. https://doi.org/10.1080/02687038.2020.1759269

\section{General rights}

Copyright and moral rights for the publications made accessible in the public portal are retained by the authors and/or other copyright owners and it is a condition of accessing publications that users recognise and abide by the legal requirements associated with these rights.

Take down policy

If you believe that this document breaches copyright please view our takedown policy at https://edshare.gcu.ac.uk/id/eprint/5179 for details

of how to contact us. 
A narrative review of communication accessibility for people with aphasia and implications for multi-disciplinary goal setting after stroke

Sophie Eleanor Brown ${ }^{\mathrm{a}^{*}}$, Marian C. Brady ${ }^{\mathrm{a}, \mathrm{b}}$, Linda Worrall ${ }^{\mathrm{b}}$, and Lesley

Scobbie $^{\mathrm{a}}$

${ }^{a}$ NMAHP Research Unit, Glasgow Caledonian University, Glasgow, UK; ${ }^{b}$ School of Health and Rehabilitation Sciences, University of Queensland, Brisbane, Australia

*Corresponding author. Email: Sophie.Brown@gcu.ac.uk 


\title{
-A narrative review of communication accessibility for people with aphasia and implications for multi-disciplinary goal setting after stroke
}

\author{
Background: Guidelines to support accessible goal setting with stroke survivors with \\ aphasia are lacking. \\ Aims: To (i) determine the communication barriers and facilitators relevant to \\ accessible goal setting for stroke survivors with aphasia and (ii) propose \\ recommendations for accessible goal setting practice. \\ Design: Narrative literature review incorporating a systematic search strategy. \\ Methods \& procedures: An electronic database search of abstracts was conducted from \\ January 2003 to March 2018 in CINAHL, MEDLINE, AMED, ProQuest Central, and \\ PsychINFO. We sought peer-reviewed articles including stroke survivors with aphasia, \\ carers, or healthcare professionals that addressed (i) communication partner skills and \\ behaviours and/or (ii) the physical environment. Study quality was appraised using the \\ Mixed Methods Appraisal Tool (MMAT). Thematic analysis was conducted on key \\ findings.
}

Outcomes \& results: 647 articles were identified. 70 full-text articles were screened for eligibility; 34 of which were included. We propose a model and recommendations to support accessible goal setting, including supportive conversation strategies and a modified physical environment.

Conclusions: Specific evidence for accessible goal setting with stroke survivors with aphasia is lacking. Staff training and ongoing support is required for successful use of communication strategies and resources. Further research is needed to develop and evaluate accessible goal setting resources and training.

Keywords: aphasia; goal setting; accessibility; rehabilitation; stroke

\section{Introduction}

Goal setting is a key component of stroke rehabilitation and involves collaboratively negotiating, pursuing, and monitoring goals for recovery (Levack et al., 2015). Goal setting is recommended in stroke rehabilitation guidelines in the UK and internationally, including the Royal College of Physicians' National Clinical Guideline for Stroke (RCP, 2016), the Australian Aphasia Rehabilitation Best Practice Statements (CCRE, 2014), the Australian 
Clinical Guidelines for Stroke Management (Stroke Foundation, 2017), and the Canadian Stroke Best Practice Recommendations (Heart and Stroke Foundation, 2018).

Levack et al. (2015) define goal setting as having two phases: goal setting and goal pursuit. Goal setting involves negotiating and setting the goals, while goal pursuit involves the activities undertaken to achieve the goals, including developing a plan, determining strategies or steps to attain the goals, and obtaining feedback (Levack et al., 2015). Explaining to stroke survivors what the goal setting process is and how they can get involved is an important preparatory activity (Scobbie et al., 2011, 2013). Goal setting in practice involves ongoing conversation (Coulter et al., 2015) between stroke survivors and rehabilitation staff to determine priorities, goals, and plans (Scobbie et al., 2013). People with aphasia have expressed a desire for greater information about stroke, aphasia, and their care pathway to empower them to engage in decision making about their rehabilitation (Worrall et al., 2011). However, many stroke survivors are not provided with written or verbal information on the goal setting process, which can be a barrier to participation (Holliday et al., 2007; Rosewilliam et al., 2011). Staff may also perceive patients with stroke and other neurological conditions as 'passive' or unwilling to participate in goal setting (Van De Weyer et al., 2010).

Supporting stroke survivors to voice what is important to them is essential to personcentred goal setting practice (Coulter et al., 2015; Scobbie et al., 2011). Speech-language therapists have emphasised the importance of this person-centredness when working with people with aphasia (Hersh et al., 2012). However, aphasia can bring additional challenges to goal setting given the communication demands of the process (Rohde et al., 2012). Further, according to previous systematic reviews addressing goal setting in rehabilitation for people with stroke and other acquired brain injuries, staff frequently cite patients' communication or 
cognitive impairments as barriers (Plant et al., 2016; Prescott et al., 2015; Rohde et al., 2012; Rosewilliam et al., 2011; Sugavanam et al., 2013).

Accessibility is key for stroke survivors with aphasia and must be integral to the goal setting process. Accessibility is defined as "the provision of flexibility to accommodate each user's needs and preferences" (Worrall, Rose, Howe, McKenna, \& Hickson, 2007). As part of the communication environment in goal setting interactions, communication partners may need to modify their communication to improve accessibility for stroke survivors with aphasia. For the purpose of this review, the communication environment consists of the communication partner, including their skills and behaviours, and the physical environment. Communication partners, such as health professionals, family members, and friends, enact skills and behaviours that impact on communication accessibility. For example, interrupting or speaking quickly may reduce communication accessibility (Simmons-Mackie, 2018). Such behaviours can be overcome by learning skills like slowing down or asking closed questions (Barnes \& Ferguson, 2015; Blom Johansson et al., 2013). Given that relationships feature prominently in the recovery goals reported by stroke survivors with aphasia, communication partners can have an important role in both facilitating access to goal setting and supporting life after stroke (Worrall et al., 2011).

The physical environment can also support or hinder the conversation. For the purpose of this review, we propose that the physical environment includes written information, pictures and images, communication support tools, and place and structure. Written information includes text formatting (i.e. font size, paragraphing, etc.) (Worrall et al., 2005). While stroke survivors with aphasia value receiving written stroke and aphasia information, the text should be formatted in an accessible way (Rose et al., 2010). Pictures and images, such as graphics, photographs, or line drawings, can also be used to support a conversation or written information (Simmons-Mackie, 2018). For example, people with 
aphasia have reported graphics as helpful in patient educational materials (Rose et al., 2011b). People with aphasia can benefit from communication tools that support their understanding and expression (Simmons-Mackie, 2018). This includes augmented and alternative communication (AAC) tools, such as symbols or picture cards. Place and structure includes the environment in which the conversation takes place, which consists of how the space is organised, noise levels, background activity, and task structures or schedules (Worrall et al., 2005).

SMARTER goal setting is a way of conceptualising the goal setting process so that it is Shared, Monitored, Accessible, Relevant, Transparent, Evolving, and Relationship-centred (Hersh et al., 2012). SMARTER, as a set of principles, aims to make collaborative goal setting easy to implement and understand for therapists and people with aphasia (Hersh et al., 2012). However, while speech-language therapists may be equipped to address the 'Accessible' component through their training as communication specialists, other members of a multi-disciplinary rehabilitation team may lack experience or confidence in making accessible adjustments (Simmons-Mackie et al., 2007).

Guidelines for multi-disciplinary rehabilitation teams on how to make goal setting conversations and the physical environment accessible for stroke survivors with aphasia are currently unavailable. Rehabilitation staff may therefore lack access to the evidence or resources to implement accessible goal setting. Consequently, stroke survivors with aphasia may not receive optimal access to goal setting in their rehabilitation. There is existing research on the preferences and goals of people with aphasia and how to approach personcentred aphasia therapy in rehabilitation (e.g. SMARTER framework). However, 36\% of community rehabilitation services in the UK operate without an SLT on staff (Scobbie et al., 2015). Therefore, the translation and uptake of this work into other disciplines that also work with people with aphasia require attention to ensure that accessible goal setting is not limited 
to only speech-language therapy settings. Our review aimed to address the lack of synthesised evidence and guidelines for improving the accessibility of multi-disciplinary goal setting by informing how stroke survivors with aphasia can be optimally supported to participate in the goal setting process through accessible communication practices.

\section{Aims}

We aimed to conduct a review of the literature in order to:

(i) determine the communication barriers and facilitators relevant to the goal setting process for stroke survivors with aphasia, including:

a) The skills and behaviours of carers and staff as communication partners and

b) The characteristics of the physical environment.

(ii) propose recommendations for accessible goal setting practice in the context of rehabilitation.

\section{Methods}

Narrative and systematic review approaches were considered. These approaches aim to provide an overview of evidence on a topic (Arksey \& O’Malley, 2005; Ferrari, 2015; Snyder \& Engström, 2016). Systematic reviews emphasise evidence quality and can provide a synthesis of evidence on a narrowly defined topic, often the effectiveness of an intervention (Dixon-Woods et al., 2005; Greenhalgh et al., 2018).

Narrative reviews provide a summary of literature and may not use quality appraisal or specific criteria for inclusion (Ferrari, 2015; Greenhalgh et al., 2018). A narrative review may be more appropriate than a systematic review when the topic is broad and includes interrelated but separately researched issues (Greenhalgh et al., 2018). The methodological rigour of narrative reviews can be enhanced by using a systematic search strategy and 
reporting the methodology in full (Ferrari, 2015; Grant \& Booth, 2009). Quality appraisal can also add credibility to the evidence gathered (Mays et al., 2005).

Thematic analysis can be used in a narrative review to provide a descriptive synthesis of qualitative and quantitative data where the objective of the review is to identify common themes on a multi-faceted topic (Braun \& Clarke, 2006; Mays et al., 2005). We chose to conduct a narrative review, using a comprehensive systematic search strategy (Ferrari, 2015; Grant \& Booth, 2009), given the wide range of topics likely to be covered within the area of accessible goal setting for stroke survivors with aphasia. Thematic analysis was used (Braun $\&$ Clarke, 2006) to inform recommendations for accessible goal setting.

\section{Search strategy}

We conducted an electronic database search of abstracts in Cumulative Index to Nursing and Allied Health Literature (CINAHL), MEDLINE, Allied and Complementary Medicine Database (AMED), ProQuest Central, and PsychINFO. These databases were selected due to their extensive coverage of medical and health science journals. Reference lists of included studies were also searched. Abstract searching was deemed the most suitable approach, as pilot searching of titles provided limited results.

Keywords were chosen to capture articles with information relevant to accessible goal setting for adult stroke survivors with aphasia and carers and healthcare staff who support them. Accessible goal setting for stroke survivors with aphasia is a broad topic involving different sub-topics that may be studied independently, such as accessible information and carer support. Articles may also address accessibility-related issues without using accessibility terminology, for example, by discussing communication support, which impacts on accessibility. The search terms were applied as keywords rather than MeSH terms due to the range of specific terms used. The keywords and search string used are provided in Appendix A. 


\section{Inclusion criteria}

Studies were included if they (i) involved adults with aphasia after stroke and/or carers and/or rehabilitation staff supporting adults with aphasia after stroke and (ii) addressed either of the following aspects of communication accessibility relevant to goal setting:

(1) The communication partner's skills and behaviours that impact on communication;

(2) Characteristics of the physical environment that impact on accessibility, including

a. written information

b. pictures or images

c. communication support tools

d. place and structure.

Articles did not need to explicitly address goal setting but needed to address at least one of the above aspects of communication accessibility. Peer-reviewed journal articles that met the above criteria and were published between January 2003 and February 2018, in English, and with full text available were considered for inclusion. Qualitative, quantitative, and mixed-methods studies were eligible for inclusion, in addition to literature reviews, and multiple case reports or vignettes. A starting year of 2003 was selected as this reflects a shift in research and practice towards conceptualising aphasia accessibility (Howe, Worall, \& Hickson, 2004). Titles of retrieved articles were screened for relevance, followed by abstracts and then full texts [EB]. A second reviewer [LS] screened full texts from $10 \%$ of the included abstracts to ensure consistency and improve rigour.

\section{Exclusion criteria}

Studies were excluded if they did not (i) address communication accessibility, (ii) state whether participants had aphasia, (iii) differentiate findings for participants with aphasia, (iv) specify aphasia after stroke (as different types of aphasia can have different aetiologies and treatment pathways not covered by stroke rehabilitation). Letters, conference proceedings, or 
single cases were also excluded. The inclusion/exclusion screening questions used are provided in Appendix B.

\section{Quality appraisal}

The Mixed Methods Critical Appraisal Tool (MMAT) (Pluye et al., 2018) was used to appraise the quality of qualitative, quantitative, and mixed-methods studies included in the review. The MMAT includes four quality criteria: clarity of research questions and objectives, sampling, appropriateness of methods, and validity of measurements or tools. A study can be given a score of $0 \%, 25 \%, 50 \%, 75 \%$, or $100 \%$. A score of $<50 \%$ is considered low quality, $75 \%$ moderate quality, and $75-100 \%$ high quality. The first author [EB] independently appraised all included studies using the MMAT tool. A second reviewer [LS] independently appraised $10 \%$ of included studies for comparison.

\section{Data extraction}

EB extracted data from all included studies into a data extraction table under the following headings: population/participant group, methods, communication partner's skills and behaviours, and characteristics of the physical environment, including a) written information, b) pictures or images, c) communication support tools, and d) place and structure (see data extraction template in Appendix C). A second reviewer [LS] independently extracted data from $10 \%$ of the included studies for comparison. Following extraction, findings were paraphrased, simplified, and categorised as barriers or facilitators [EB].

\section{Data synthesis}

We used a two-stage thematic analysis process (Braun \& Clarke, 2006) to summarise the main themes derived from the extracted findings. In the first stage of analysis, a deductive approach was used. Findings were grouped by the first author [EB] as barriers or facilitators 
in relation to the pre-existing categories of (i) communication partner skills and behaviours and (ii) physical environment. Preliminary themes, sub-themes, and codes were identified after repeated reading of the data [EB], then reviewed and discussed [EB, LS], resulting in similar themes and sub-themes being merged. To be considered as recommendations, findings needed to be reported by a study rated as moderate or high quality (75-100\%) with the MMAT.

In the second phase of analysis, relationships were examined between the barrier and facilitator themes and sub-themes [EB]. This informed development of a proposed model for accessible goal setting. The model was discussed and refined with three other reviewers [LS, $\mathrm{MB}, \mathrm{LW}]$ with reference to barrier and facilitator themes and subthemes.

\section{Results}

As illustrated in Figure 1, 647 articles were assessed for eligibility after excluding 145 duplicates. A total of 70 full-text articles were assessed against the inclusion criteria, including 55 articles identified from the database search and a further 15 articles identified through other sources. A total of 36 articles were excluded. Thus, 34 articles were included in the analysis. In two instances, two separate articles reported different data sets from the same study (Croteau et al., 2004; Croteau \& Le Dorze, 2006; Rose et al., 2011a, 2012), resulting in a total of 32 studies included in our review. A list of included studies and MMAT quality scores is provided in Appendix D. 


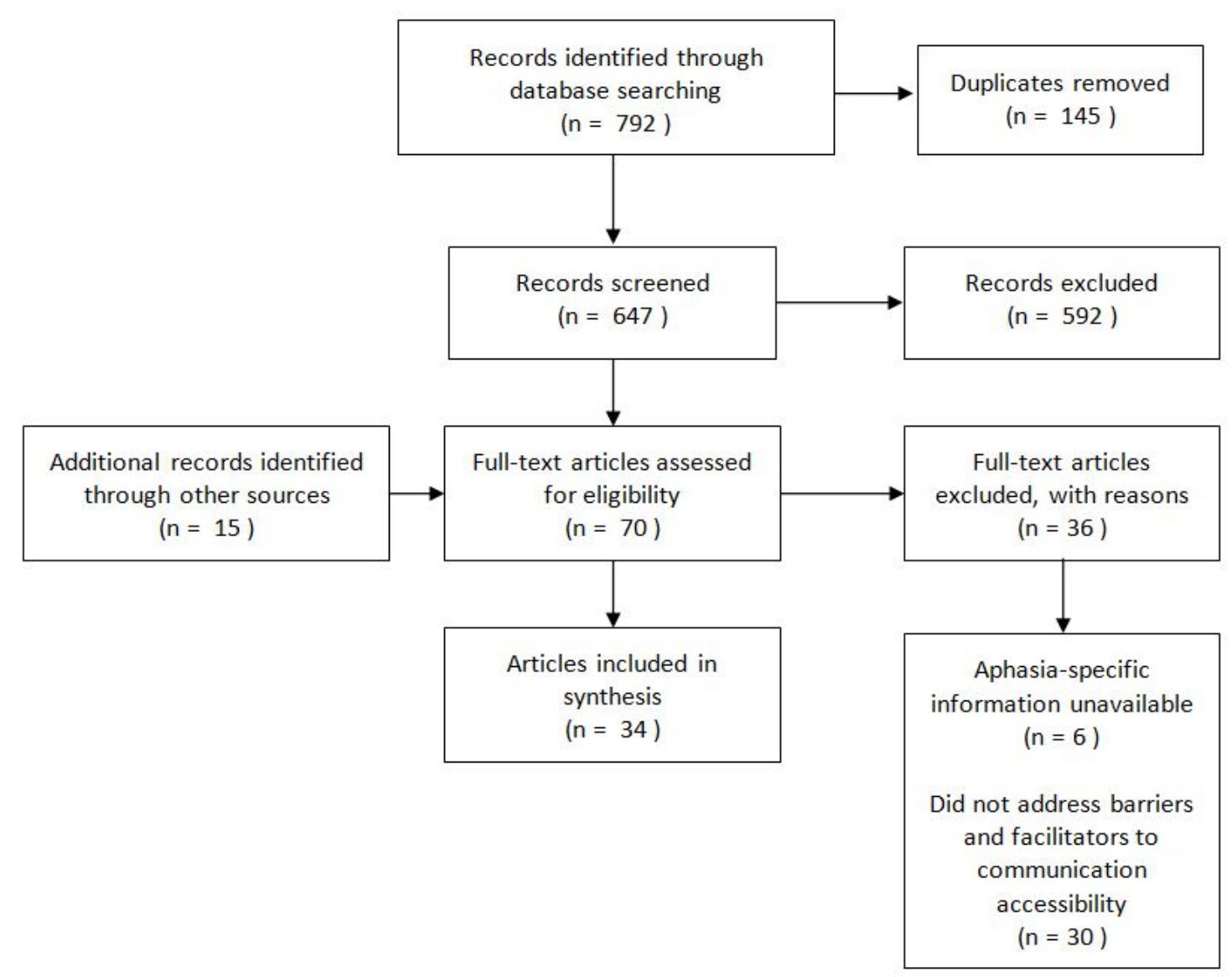

Figure 1. PRISMA diagram

\section{Study design}

The majority of studies ( $\mathrm{n}=17)$ used qualitative methods, including interviews, case studies, observations, and literature reviews. Four studies used quantitative methods, including surveys and pre-/post-training assessments. Eight studies used mixed methods designs, largely involving combinations of interviews and surveys or other assessment data. Two studies about the Talking Mats ${ }^{\mathrm{TM}}$ communication tool (Bornman \& Murphy, 2006; Murphy \& Boa, 2012) presented case vignettes, and one study was an opinion piece (SimmonsMackie, 2018). 


\section{Study quality}

Overall, the quality of included studies was high (see Appendix E). No studies were excluded from analysis based on quality. Three studies could not be classified or appraised (Bornman \& Murphy, 2006; Murphy \& Boa, 2012; Simmons-Mackie, 2018) as case vignettes and opinion pieces are not included in the MMAT appraisal tool. Four included studies (15\%) were independently appraised by a second reviewer [LS] to ensure consistency for compiling recommendations. Agreement for quality scores was reached for all four jointly appraised articles.

Of the 30 studies appraised, 14 scored 100\% (high quality and methodological rigour). Twelve studies scored $75 \%$, indicating moderate quality. Three studies (Dalemans, De Witte, Wade, \& Van den Heuvel, 2008; Purdy \& Hindenlang, 2005; Blom Johansson et al., 2013) scored 50\%, indicating low quality. Of these, one study (Purdy \& Hindenlang, 2005) did not provide the sampling strategy and lacked sufficient information about the caregiver and stroke survivor communication assessments and questionnaires used. The second study (Dalemans et al., 2008) used mixed methods, but the aims and methods of the quantitative study contained insufficient detail, so only data from the qualitative study was extracted. The third study (Blom Johansson et al., 2013) used mixed methods, but the qualitative component provided insufficient information about the context of data collection and researcher reflexivity. 


\section{Communication barriers and facilitators relevant to accessible goal setting}

Studies addressed a range of accessibility issues within the two domains of communication partner skills and behaviours and the characteristics of the physical environment. Ten studies addressed communication partner skills and behaviours only, 12 studies addressed physical environment only, and ten studies addressed both. Of the studies on the physical environment, 13 addressed written information, eight addressed pictures and images, five addressed communication support tools, and nine addressed place and structure. Table 1 presents communication partner and physical environment themes with related barrier and facilitator sub-themes and codes. 
Table 1. Themes, sub-themes, and codes for communication partner and physical environment barriers and facilitators

\begin{tabular}{|c|c|c|}
\hline $\begin{array}{l}\text { Communication } \\
\text { partner themes }\end{array}$ & Barrier sub-themes & Facilitator sub-themes \\
\hline $\begin{array}{l}\text { (1) Implementation } \\
\text { of accessibility } \\
\text { strategies }\end{array}$ & $\begin{array}{l}\text { Service-level barriers } \\
\text { - Lack of training and awareness (Hilton, Leenhouts, Webster, } \\
\text { \& Morris, 2014; Howe, Worrall, \& Hickson, 2008a; Jensen et al., } \\
\text { 2015; Simmons-Mackie et al., 2007) } \\
\text { - Lack of staff continuity (Simmons-Mackie \& Kagan, 2007) }\end{array}$ & $\begin{array}{l}\text { Service-level support } \\
+ \text { Centralised support team (Simmons-Mackie \& Kagan, 2007) } \\
+ \text { Ongoing training and support (Horton, Lane, \& Shiggins, 2016; } \\
\text { Jensen et al., 2015; Simmons-Mackie et al., 2007) }\end{array}$ \\
\hline (2) Time & $\begin{array}{l}\text { Lack of time } \\
\text { - Not enough time given to the conversation (Hersh, Godecke, } \\
\text { Armstrong, Ciccone, \& Bernhardt, 2016; Horton et al., 2016; } \\
\text { Jensen et al., 2015) } \\
\text { - Fast pacing of the conversation (Ashton et al., 2008; Croteau, } \\
\text { Vychytil, Larfeuil, \& Le Dorze, 2004; O'Halloran, Worrall, \& } \\
\text { Hickson, 2011; Purdy \& Hindenlang, 2005) }\end{array}$ & $\begin{array}{l}\text { Enough time } \\
\text { + More time given to the conversation (Blom Johansson, Carlsson, } \\
\text { Östberg, \& Sonnander, 2012; Blonski et al., 2014; Dalemans et al., } \\
\text { 2008; Grohn, Worrall, Simmons-Mackie, \& Brown, 2012; Howe et al., } \\
\text { 2008a; Howe, Worrall, \& Hickson, 2008b; Jensen et al., 2015; Blom } \\
\text { Johansson, Carlsson, \& Sonnander, 2012; Luck \& Rose, 2007) } \\
\text { + Slow pacing of the conversation (Blom Johansson et al., 2012; } \\
\text { Grohn et al., 2012; Howe et al., 2008a; Purdy \& Hindenlang, 2005) }\end{array}$ \\
\hline $\begin{array}{l}\text { (3) Participation of } \\
\text { the person with } \\
\text { aphasia }\end{array}$ & $\begin{array}{l}\text { Excluding the person with aphasia } \\
\text { - Controlling the conversation (Croteau et al., 2004; Hersh et al., } \\
\text { 2016; Jensen et al., 2015; Blom Johansson et al., 2012.; Purdy \& } \\
\text { Hindenlang, 2005; Simmons-Mackie et al., 2007) } \\
\text { - "Speaking for" the person with aphasia (Croteau \& Le } \\
\text { Dorze, 2006; Croteau et al., 2004; Dalemans et al., 2008; Hersh et } \\
\text { al., 2016; Howe et al., 2008a; Jensen et al., 2015) }\end{array}$ & $\begin{array}{l}\text { Including the person with aphasia } \\
+ \text { Giving opportunities to communicate (Grohn et al., 2012; Hersh et } \\
\text { al., 2016; O'Halloran et al., 2011) } \\
\text { + Managing "speaking for" behaviours (Hersh et al., 2016) }\end{array}$ \\
\hline $\begin{array}{l}\text { (4) Conversation } \\
\text { partner's approach } \\
\text { to strategies }\end{array}$ & $\begin{array}{l}\text { Negative approach to strategies from staff/carers } \\
\text { - Negative attitude/impatience (Howe et al., 2008a; Jensen et al., } \\
\text { 2015; Simmons-Mackie et al., 2007) } \\
\text { - Avoiding strategies (Hilton et al., 2014; Blom Johansson et al., }\end{array}$ & $\begin{array}{l}\text { Positive approach to strategies from staff/carers } \\
\text { + Positive staff/carer attitude when using strategies (Horton et al., } \\
\text { 2016; Howe et al., 2008a, 2008b; Blom Johansson et al., 2012; Purdy \& } \\
\text { Hindenlang, 2005) }\end{array}$ \\
\hline
\end{tabular}




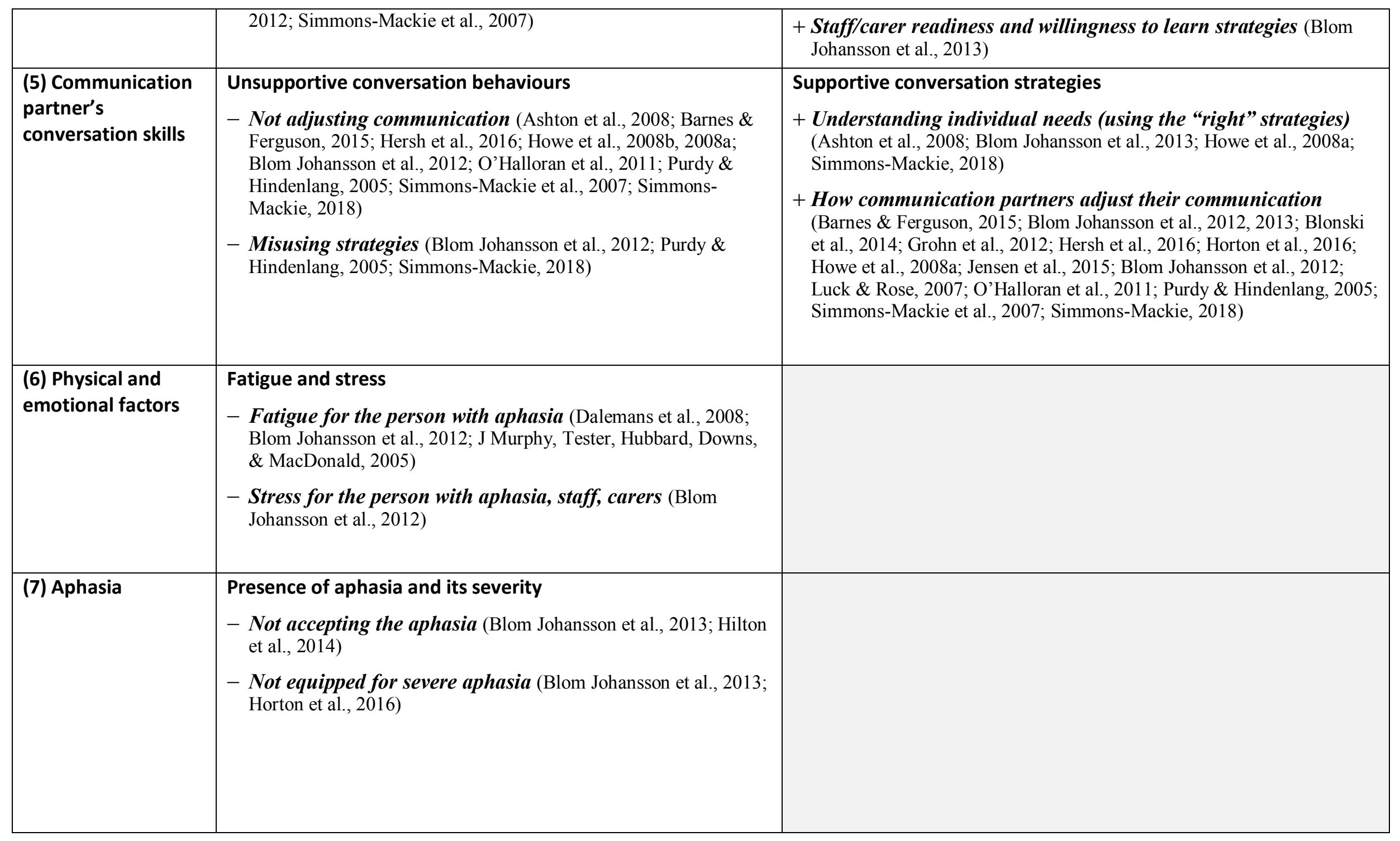




\begin{tabular}{|c|c|c|}
\hline \multirow{2}{*}{$\begin{array}{l}\text { Physical } \\
\text { environment } \\
\text { themes }\end{array}$} & Barrier sub-themes & Facilitator sub-themes \\
\hline & Unsupportive physical environment & Supportive physical environment \\
\hline $\begin{array}{l}\text { (1) Written } \\
\text { information }\end{array}$ & $\begin{array}{l}\text { - Complex information (Ashton et al., 2008; Eames, McKenna, } \\
\text { Worrall, \& Read, 2003; Greig, Harper, Hirst, Howe, \& Davidson, } \\
\text { 2008; Howe et al., 2008b) } \\
\text { - Complicated format (font/ layout) (Eames et al., 2003; Greig } \\
\text { et al., 2008; Hoffmann \& McKenna, 2006; Howe et al., 2008a; } \\
\text { Rose, Worrall, Hickson, \& Hoffmann, 2011a) }\end{array}$ & $\begin{array}{l}\text { + Simple and consistent written information (Ashton et al., 2008; } \\
\text { Brandenburg, Worrall, Copland, \& Rodriguez, 2017; Eames et al., } \\
\text { 2003; Egan, Worrall, \& Oxenham, 2004; Hoffmann \& McKenna, 2006; } \\
\text { Howe et al., 2008a; Purdy \& Hindenlang, 2005; Rose et al., 2011; Rose, } \\
\text { Worrall, \& McKenna, 2003) } \\
+ \text { Clear format (font/layout/colour) (Brandenburg et al., 2017; Grohn } \\
\text { et al., 2012; Howe et al., 2008a; Rose et al., 2011; Rose, Worrall, } \\
\text { Hickson, \& Hoffmann, 2012; Rose et al., 2003) }\end{array}$ \\
\hline $\begin{array}{l}\text { (2) Pictures and } \\
\text { images }\end{array}$ & $\begin{array}{l}\text { - Lack of clear visual aids (Eames et al., 2003; Greig et al., 2008) } \\
\text { - Negative perceptions of pictures (Rose et al., 2011, 2012; Rose } \\
\text { et al., 2003) }\end{array}$ & $\begin{array}{l}\text { + Relevant pictures and images to support text (Dalemans et al., } \\
\text { 2008; Dietz, Hux, McKelvey, Beukelman, \& Weissling, 2009; Eames et } \\
\text { al., 2003; Greig et al., 2008; Howe et al., 2008a; Rose et al., 2011, 2012 } \\
\text { Rose et al., 2003) } \\
+ \text { Giving choice (Rose et al., 2012) }\end{array}$ \\
\hline $\begin{array}{l}\text { (3) Communication } \\
\text { support tools }\end{array}$ & $\begin{array}{l}\text { - Technology (Dietz et al., 2013) } \\
\text { - Communicating abstract ideas (Murphy \& Boa, 2012) }\end{array}$ & $\begin{array}{l}\text { + Concrete visual representations (Dietz et al., 2013; Grohn et al., } \\
\text { 2012; Murphy et al., 2005; Murphy \& Boa, 2012) } \\
+ \text { Considering options and making decisions (Bornman \& Murphy, } \\
\text { 2006; Murphy \& Boa, 2012) }\end{array}$ \\
\hline $\begin{array}{l}\text { (4) Place and } \\
\text { structure }\end{array}$ & $\begin{array}{l}\text { - Busy or noisy environment (Egan et al., 2004; Horton et al., } \\
\text { 2016; Howe et al., 2008a; Blom Johansson et al., 2012) } \\
\text { - Unfamiliar environment (Howe et al., 2008a, 2008b; Blom } \\
\text { Johansson et al., 2012) }\end{array}$ & $\begin{array}{l}+ \text { Quiet (Howe et al., 2008a) } \\
+ \text { Structured and tailored tasks (Ashton et al., 2008; Blonski et al., } \\
\text { 2014; Howe et al., 2008b; O'Halloran et al., 2011) }\end{array}$ \\
\hline
\end{tabular}




\section{Communication partner}

Seven communication partner themes were identified, consisting of seven barrier and five facilitator sub-themes (see Table 1). Each theme is presented below, with reference to related sub-themes.

1. "Implementation of accessibility strategies". Service level barriers and support impacted on implementation of accessibility strategies for people with aphasia.

Service-level barriers included lack of training and awareness of accessibility strategies, and lack of rehabilitation staff continuity. A lack of understanding of aphasia, accessibility, and how to accommodate communication needs was reported by four articles (Hilton et al., 2014; Howe et al., 2008a; Jensen et al., 2015; Simmons-Mackie et al., 2007). A qualitative evaluation of a team-based staff training intervention to improve aphasia accessibility in acute, rehabilitation, and long-term care settings found that staff tended to view communicative access as the responsibility of speech and language therapists (SLTs) (Simmons-Mackie et al., 2007).

In their synthesis of literature on the views of family members on aphasia intervention needs, Hilton et al. (2014) found that family members reported inadequate understanding and education about aphasia to implement communication strategies (Hilton et al., 2014). Howe et al.'s (2008a) qualitative study investigating environmental factors influencing community participation for people with aphasia and Jensen et al.'s (2015) mixed methods study implementing communication partner training for nursing staff in an inpatient stroke unit similarly reported that a lack of knowledge about communication needs negatively impacted on accessibility. Simmons-Mackie et al. (2007) highlighted that high staff turnover could also be a barrier to implementing accessible strategies, as it would increase training demands. 
Service-level support included having a centralised support team and ongoing training and support. Having a dedicated aphasia team or trainers from among the rehabilitation staff, responsible for supporting accessibility strategies and training, was found to facilitate accessibility strategy implementation in a long-term residential care facility (Simmons-Mackie et al., 2007).

Continued staff training and support, rather than one-off training workshops, also appeared important to maintain accessible practice (Horton et al., 2016; Jensen et al., 2015; Simmons-Mackie et al., 2007). Horton et al. (2016) conducted a qualitative study evaluating supported communication training with multi-disciplinary stroke unit staff. Training consisted of workshops utilising video examples and individual and group sessions delivered by a person trained in supported communication techniques (e.g. SCA ${ }^{\mathrm{TM}}$ ) and feedback from people with aphasia (Horton et al., 2016). Additional support such as learning logs and training reviews were included (Horton et al., 2016). Findings suggested that the training workshops could help to achieve and sustain a culture of inclusivity for people with aphasia in stroke rehabilitation units (Horton et al., 2016).

2. "Time" addressed the need for time to make communication accessible. Lack of time included not enough time given to the conversation and fast pacing of the conversation. In three studies, healthcare staff reported frustration with the extra time taken in conversation with stroke survivors with aphasia (Hersh, Godecke, Armstrong, Ciccone, \& Bernhardt, 2016; Horton et al., 2016; Jensen et al., 2015). Staff working in inpatient stroke and rehabilitation units also reported scheduling constraints and limited time with individual patients as barriers to implementing supported communication strategies (Horton et al., 2016; Simmons-Mackie et al., 2007). Horton et al. (2016) 
found that some staff members felt their time management improved following supported communication training.

Barriers reported by people with aphasia included communication partners speaking too quickly and not allowing enough time for them to speak or process information (Ashton et al., 2008; Blonski et al., 2014; Croteau et al., 2004; Blom Johansson, Carlsson, \& Sonnander, 2012; O’Halloran et al., 2011; Purdy \& Hindenlang, 2005). In an ethnographic study of a hospital stroke ward, O'Halloran et al. (2011) observed that nurses tended to limit talk to practical tasks and rush interactions with patients with aphasia.

A communication environment with enough time included more time given to the duration and pacing of the conversation. Communication partners providing extra time and slowing their rate of speech were reported as facilitators in eight studies set in a range of settings and including interactions with carers, staff members, and people with aphasia (Blom Johansson, Carlsson, Östberg, \& Sonnander, 2012; Blonski et al., 2014; Dalemans et al., 2008; Grohn, Worrall, Simmons-Mackie, \& Brown, 2012; Howe et al., 2008a; Howe, Worrall, \& Hickson, 2008b; Blom Johansson, Carlsson, \& Sonnander, 2012; Luck \& Rose, 2007).

3. "Participation of the person with aphasia" addressed issues of inclusion. Excluding the person with aphasia involved controlling the conversation and "speaking for" them. Carers or staff were observed "holding the floor" or directing the conversation in response to the stroke survivor with aphasia's communication difficulties (Croteau et al., 2004; Hersh et al., 2016; Jensen et al., 2015; Blom Johansson et al., 2012; Purdy \& Hindenlang, 2005; Simmons-Mackie et al., 2007).

Staff enacted "speaking for" behaviours by speaking to carers instead of involving the person with aphasia, particularly when the aphasia was severe (Croteau \& 
Le Dorze, 2006; Croteau et al., 2004; Dalemans et al., 2008; Hersh et al., 2016; Howe et al., 2008a; Jensen et al., 2015). Hersh et al. (2016) investigated nurses' interactions with stroke survivors on an acute stroke ward. They found that the presence of a family member reduced the engagement of a patient with severe aphasia in conversations with the nurse and that increased engagement was noted when the family member was absent (Hersh et al., 2016). Croteau et al. (2004) observed conversations between stroke survivors with aphasia and carers to measure "speaking for" behaviours and found that some spouses engaged in behaviours such as answering questions directed to the person with aphasia and contributing to conversations without invitation.

Including the person with aphasia involved giving opportunities to communicate and managing "speaking for" behaviours. Grohn et al. (2012) and O’Halloran et al. (2011) found that communication was facilitated when stroke survivors with aphasia were actively included and given the chance to communicate in a way that suited them. Hersh et al. (2016) found that staff could also manage carers or others "speaking for" the person with aphasia by re-directing the conversation back to the person with aphasia and avoiding speaking only to the carer.

4. "Communication partner's approach to strategies" addressed how staff and carers approached learning and using communication strategies with stroke survivors with aphasia. A negative approach to strategies from staff/carers included having a negative attitude, being impatient, or avoiding strategies. Hilton et al. (2014) found that some family members were reluctant to use strategies because they did not want to focus on the stroke survivor's communication impairment, as their focus was on recovery, or they wanted to protect the feelings of the person with aphasia.

In their study implementing the Supported Conversation for adults with Aphasia (SCA $\left.{ }^{\mathrm{TM}}\right)$ technique with inpatient stroke unit staff, Jensen et al. (2015) found that prior 
to training, staff perceived that strategies would not be useful. Both Jensen et al. (2015) and Simmons-Mackie et al. (2007) found a tendency for staff and carers to meet communication difficulties with impatience or frustration.

Having a positive approach to strategies from staff/carers included staff/carer readiness and willingness to learn and use strategies (Blom Johansson et al., 2013). Several studies also reported that having a positive attitude was helpful, and this could take the form of showing interest (Blom Johansson et al., 2012), being prepared to be wrong (Horton et al., 2016), and being sensitive to frustration from the person with aphasia (Purdy \& Hindenlang, 2005).

5. "Communication partner's conversation skills" addressed communication partners' behaviours and strategies that influenced the accessibility of a conversation. Unsupportive conversation behaviours included not adjusting communication and misusing strategies. Communication partners rapidly firing questions (Purdy \& Hindenlang, 2005), not using eye contact (Purdy \& Hindenlang, 2005), and giving up conversations when they were difficult (Blom Johansson et al., 2012; Purdy \& Hindenlang, 2005; Simmons-Mackie et al., 2007) were examples of not adjusting communication. Misusing strategies included over-use or incorrect use of strategies, such as using too many gestures or an excessively slow rate of speech (Blom Johansson et al., 2012; Purdy \& Hindenlang, 2005; Simmons-Mackie, 2018).

Supportive conversation strategies included understanding individual needs (using the right strategies) and how communication partners adjusted their communication. Understanding the individual's aphasia and tailoring communication accordingly were reported as facilitators by four studies (Ashton et al., 2008; Blom Johansson et al., 2013; Howe et al., 2008a; Simmons-Mackie, 2018). Ashton et al. 2008) observed barriers and facilitators for people with aphasia using public transport. 
Examples of facilitators included personalised travel information, such as specific route and map printouts for a person's journey and drivers and staff accommodating communication needs (Ashton et al., 2008).

Several studies reported specific communication strategies, also called supported conversation techniques, such as using closed questions and asking them one at a time (Blom Johansson et al., 2012; Horton et al., 2016; Jensen et al., 2015), checking that the person with aphasia and the communication partner had understood each other (Blom Johansson et al., 2012; Grohn et al., 2012; Horton et al., 2016; Jensen et al., 2015; Luck \& Rose, 2007; O’Halloran et al., 2011), and re-phrasing or paraphrasing responses (Luck \& Rose, 2007; O’Halloran et al., 2011; Purdy \& Hindenlang, 2005).

6. "Physical and emotional factors" related to stress and fatigue. Stroke survivors with aphasia reported that their own stress and fatigue increased their communication difficulties, e.g. struggling to find the right word or focus on the conversation (Dalemans et al., 2008; Blom Johansson et al., 2012; Murphy et al., 2005). Dalemans et al. (2008) explored social participation for stroke survivors with aphasia and found that fatigue was a barrier to participating in interview conversations. Nonverbal signs of fatigue were important signals to communication partners. Staff and carer stress was also found to have a negative impact on conversations (Blom Johansson et al., 2012). There were no facilitators reported for this theme.

7. "Aphasia" included carers and health professionals' perspectives on the presence of aphasia and its severity. Non-SLT staff, such as nurses, reported aphasia as a barrier and believed that they did not have the tools and skills to accommodate the communication needs of stroke survivors with severe aphasia (Blom Johansson et al., 2013; Horton et al., 2016). Blom Johansson et al. (2013) and Hilton et al. (2014) found that some carers wanted the impairment to improve before using strategies. 
Consequently, they were not receptive to SLT explanations of the impact of aphasia and importance of strategies. There were no facilitators reported for this theme.

\section{Physical environment}

Four physical environment themes were identified, including eight barrier and eight facilitator sub-themes (see Table 1). Each theme is presented below, with reference to related sub-themes.

1. "Written information" barriers included complex information and complicated format (font/ layout). The use of complex or technical language was reported as a barrier by stroke survivors with aphasia (Ashton et al., 2008; Eames, McKenna, Worrall, \& Read, 2003; Greig, Harper, Hirst, Howe, \& Davidson, 2008; Howe et al., 2008b). Ashton et al. (2008) found that some people with aphasia struggled to read transport information such as timetables due to complicated formatting and too much information. Formatting barriers included too much text (Eames et al., 2003; Greig et al., 2008; Rose et al., 2011a), small font (Eames et al., 2003; Greig et al., 2008; Hoffmann \& McKenna, 2006; Rose et al., 2011a), and a complicated layout making it difficult to distinguish sections or key information (Eames et al., 2003; Hoffmann \& McKenna, 2006; Howe et al., 2008a; Rose et al., 2011a).

"Written information" facilitators included simple and consistent written information and clear format (font/layout/ colour). Straight to the point, simple, and consistent language made text more accessible (Ashton et al., 2008; Eames et al., 2003; Howe et al., 2008a; Rose et al., 2011a; Rose et al., 2003). Accessible or “aphasiafriendly" formatting principles included san-serif font, large font (more than 12-point) (Grohn et al., 2012; Rose et al., 2011a, 2012; Rose et al., 2003), at least 1.5 line spacing and space between paragraphs (Howe et al., 2008a; Rose et al., 2011a, 2012; Rose et al., 
2003), and highlighting key information using bold, capitals, underlining, and colour coding (Brandenburg et al., 2017; Rose et al., 2011a).

2. "Pictures and images" barriers included lack of clear visual aids and negative perceptions of pictures. Not having pictures to support text or having pictures that were difficult to interpret were reported as barriers for people with aphasia (Eames et al., 2003; Greig et al., 2008). Two studies (Rose et al., 2012; Rose et al., 2003) found that most stroke survivors with aphasia surveyed found pictures helpful to accompany text. However, Rose et al. (2011a), evaluating the acceptability of different types of aphasiafriendly patient education materials, reported that some participants found written materials with a high volume of pictures to be childish and embarrassing.

Including relevant pictures and images to support text and giving choice facilitated understanding for people with aphasia. High-context or relevant pictures that could be easily interpreted were favoured. Pictures were generally preferred to no pictures, graphics were preferred to line drawings, and colour photographs were preferred to graphics (Dietz et al., 2009; Rose et al., 2011a, 2012; Rose et al., 2003). However, the findings from the above studies also emphasised the need for choice, as not all stroke survivors with aphasia appreciated or needed the same level of accessible materials (Rose et al., 2012).

3. "Communication support tools" barriers included technology and communicating abstract ideas. A qualitative study exploring carers' and stroke survivors' views on alternative and augmentative communication (AAC) found that some carers struggled to understand the artificial speech output produced by high-tech AAC devices (Dietz et al., 2013). Murphy and Boa (2012) reported case vignettes describing goal setting with people with communication difficulties. They reported that in the context of goal setting conversations, communicating and determining priorities 
with stroke survivors with aphasia was difficult without support tools due to the need to discuss abstract ideas, such as hopes or aims for recovery (Murphy \& Boa, 2012).

"Communication support tools" facilitators included the availability of concrete visual representations and tools such as pictures and symbols to support considering options and making decisions. Three studies described Talking Mats ${ }^{\mathrm{TM}}$, a support tool that uses picture/symbol cards placed on a mat to facilitate conversations and decision making with people with communication difficulties (Bornman \& Murphy, 2006; Murphy et al., 2005; Murphy \& Boa, 2012). Having pictures that stroke survivors could take ownership of and physically place on a mat assisted in identifying topics and priorities for discussion during goal setting conversations, such as communication and self-care (Murphy et al., 2005; Murphy \& Boa, 2012). Using the picture cards and predetermined topic areas, stroke survivors could review the options in front of them and make decisions about goals they wanted to pursue (Bornman \& Murphy, 2006; Murphy \& Boa, 2012).

4. "Place and structure" barriers included a busy or noisy environment and an unfamiliar environment. Distractions in the form of noise or background activity impacted on communication for people with aphasia, as it made it more difficult to focus on the conversation (Egan et al., 2004; Horton et al., 2016; Howe et al., 2008a; Blom Johansson et al., 2012). Unfamiliar places and situations such as seeing a new doctor required more cognitive processing, leaving less focus available for communication (Howe et al., 2008a, 2008b; Blom Johansson et al., 2012).

"Place and structure" facilitators included quiet and structured and tailored tasks. A quiet environment allowed stroke survivors with aphasia to focus on the conversation (Howe et al., 2008a). Tailored tasks with a consistent structure were reported to reduce the cognitive load and improve communication accessibility (Ashton 
et al., 2008; Blonski et al., 2014; Howe et al., 2008b; O’Halloran et al., 2011). Blonski et al. (2014) conducted a qualitative study exploring experiences of stroke survivors with aphasia participating in community exercise programmes. Stroke survivors reported that consistent class formats in a community exercise programme and tailoring exercises to suit individual needs facilitated access and participation for them (Blonski et al., 2014).

\section{Model to support accessible goal setting}

Further analysis of the interrelationships between the main themes informed development of a proposed model for accessible goal setting (Figure 2). The model outlines what can be considered to enhance accessible goal setting practice for stroke survivors with aphasia.

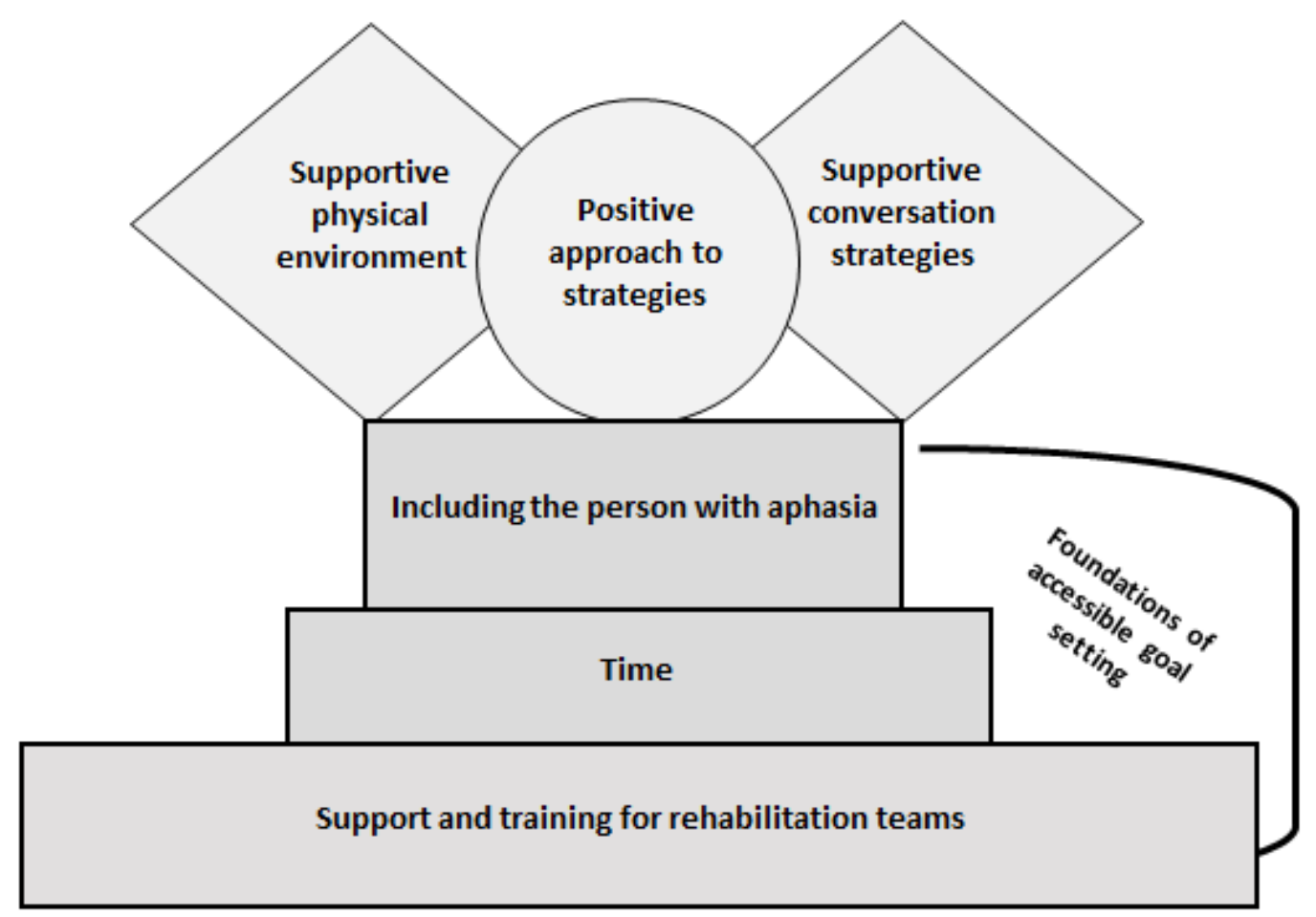

Figure 2. Proposed model to support accessible goal setting practice

Supportive physical environment and supportive conversation strategies sit at 
the top of the model. Although we propose that they are essential for an accessible goal setting process, our findings suggest that without the support of the foundation components, their optimal use and ongoing implementation will be compromised.

The main foundation of the model, support and training for rehabilitation teams, includes the training and ongoing support needed for rehabilitation staff to implement accessible goal setting. Components higher up in the model, such as supportive conversation strategies, may not be implemented effectively or at all without training (Jensen et al., 2015; Simmons-Mackie et al., 2007).

We propose that sufficient time needs to be allocated to interactions between staff, stroke survivors with aphasia, and carers to have appropriately paced, supportive goal setting conversations. Staff are often bound by tight schedules (Horton et al., 2016; Jensen et al., 2015; Simmons-Mackie et al., 2007), which could affect their ability to allow the additional time needed for supportive goal setting conversations.

Results indicated a tendency among healthcare staff and carers to exclude people with aphasia from conversations (Croteau \& Le Dorze, 2006; Croteau et al., 2004; Dalemans et al., 2008; Hersh et al., 2016). The third foundation component is therefore including the person with aphasia, a necessary pre-requisite for a supportive physical environment and conversation strategies.

The three foundations of the model facilitate a supportive physical environment, positive approach to strategies, and supportive conversation strategies. A positive approach to strategies is enacted by being open to learning strategies, respectful, and sensitive to communication challenges faced by people with aphasia (Blom Johansson et al., 2013; Horton et al., 2016; Blom Johansson et al., 2012; Purdy \& Hindenlang, 2005). This could encourage flexibility and willingness to problem solve, which may be required in the context of goal setting to adapt to individual needs. 
Supportive physical environment involves creating quiet and familiar places and task structures (e.g. using a predictable format and questions for setting goals and checking in with progress) as the basis for communication support tools and goal setting resources that utilise modified written information and images (see Table 1).

Supportive physical environment is balanced with supportive conversation strategies (see Table 1). Results indicated that verbal or conversation support was helpful for explaining written material (Howe et al., 2008a), and written material was helpful for understanding conversations (Howe et al., 2008a; Purdy \& Hindenlang, 2005). Rehabilitation staff can use both a supportive physical environment (with specific and flexible resources) and supportive conversation strategies as part of goal setting conversations to help stroke survivors with aphasia to participate successfully in rehabilitation.

\section{Recommendations to inform accessible goal setting practice}

In Table 2, we present our evidence-based recommendations for a supportive physical environment and supportive conversation strategies, formulated from the barriers and facilitators identified in the first stage of analysis. Both the goal setting and goal pursuit phases of the goal setting process involve conversation and take place in a physical environment. Our recommendations include methods for adapting the physical environment and supportive conversation strategies to make goal setting conversations and resources more accessible for stroke survivors with aphasia.

(Table 2 here - landscape pages) 
Table 2. Recommendations to inform accessible goal setting for stroke survivors with aphasia

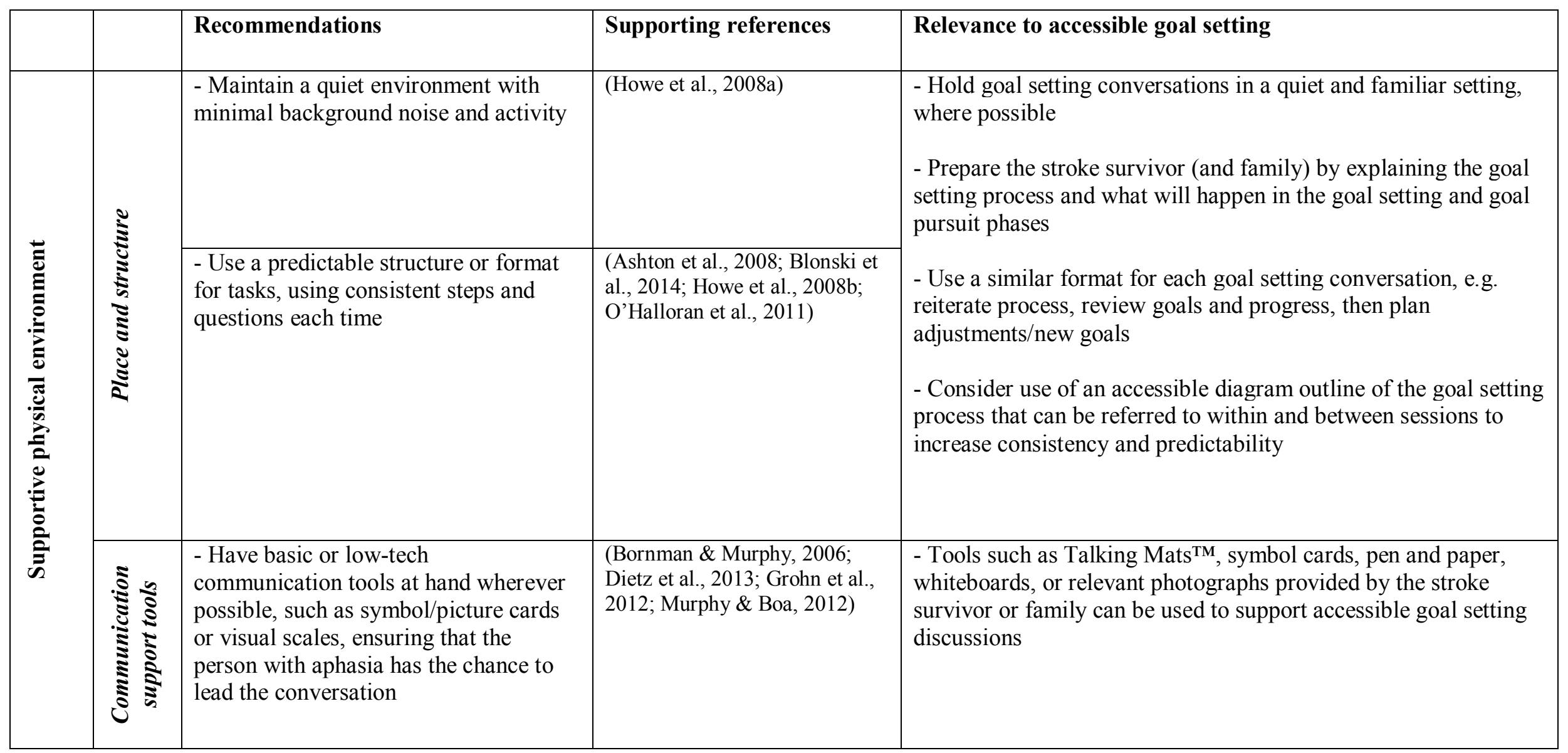




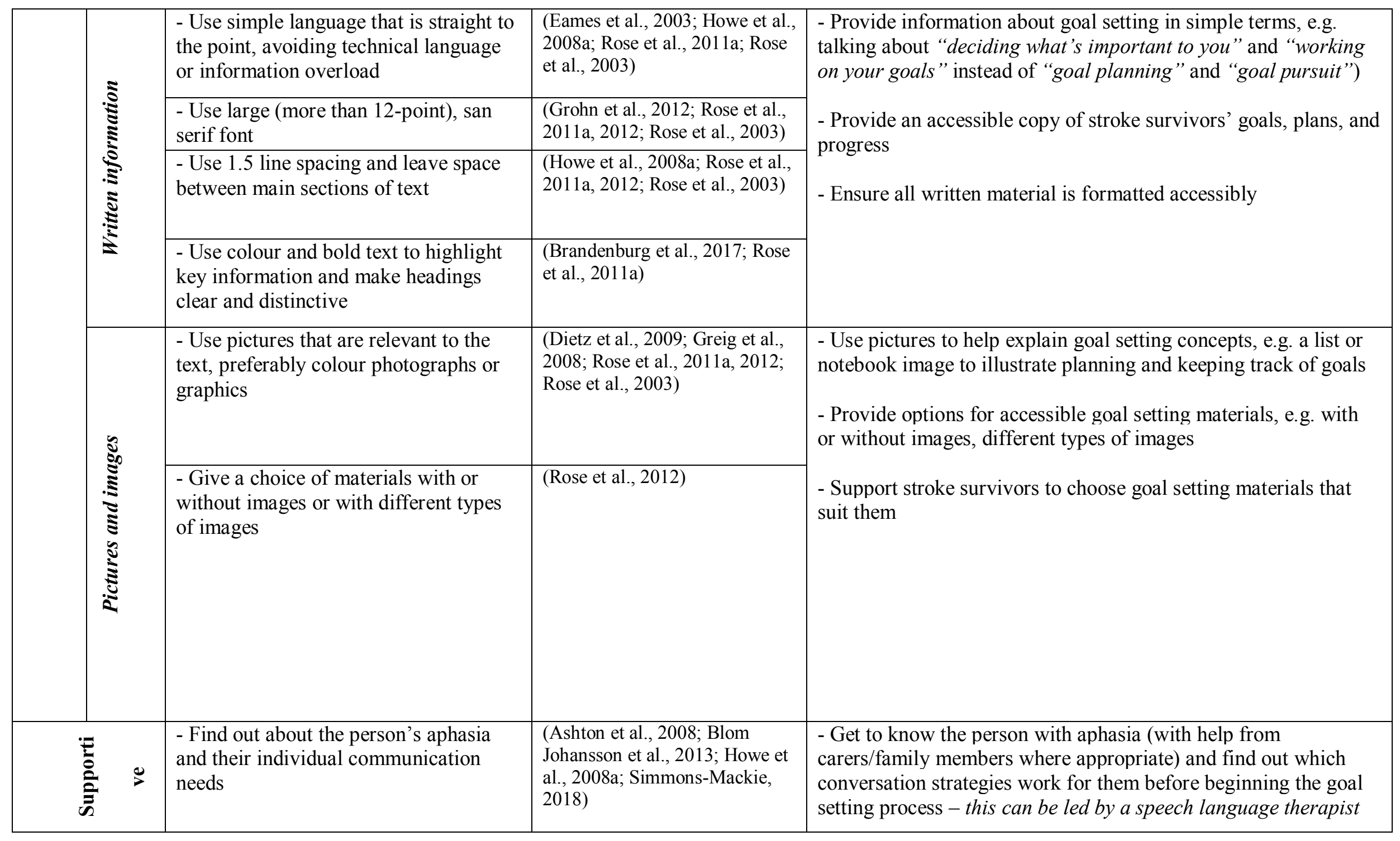




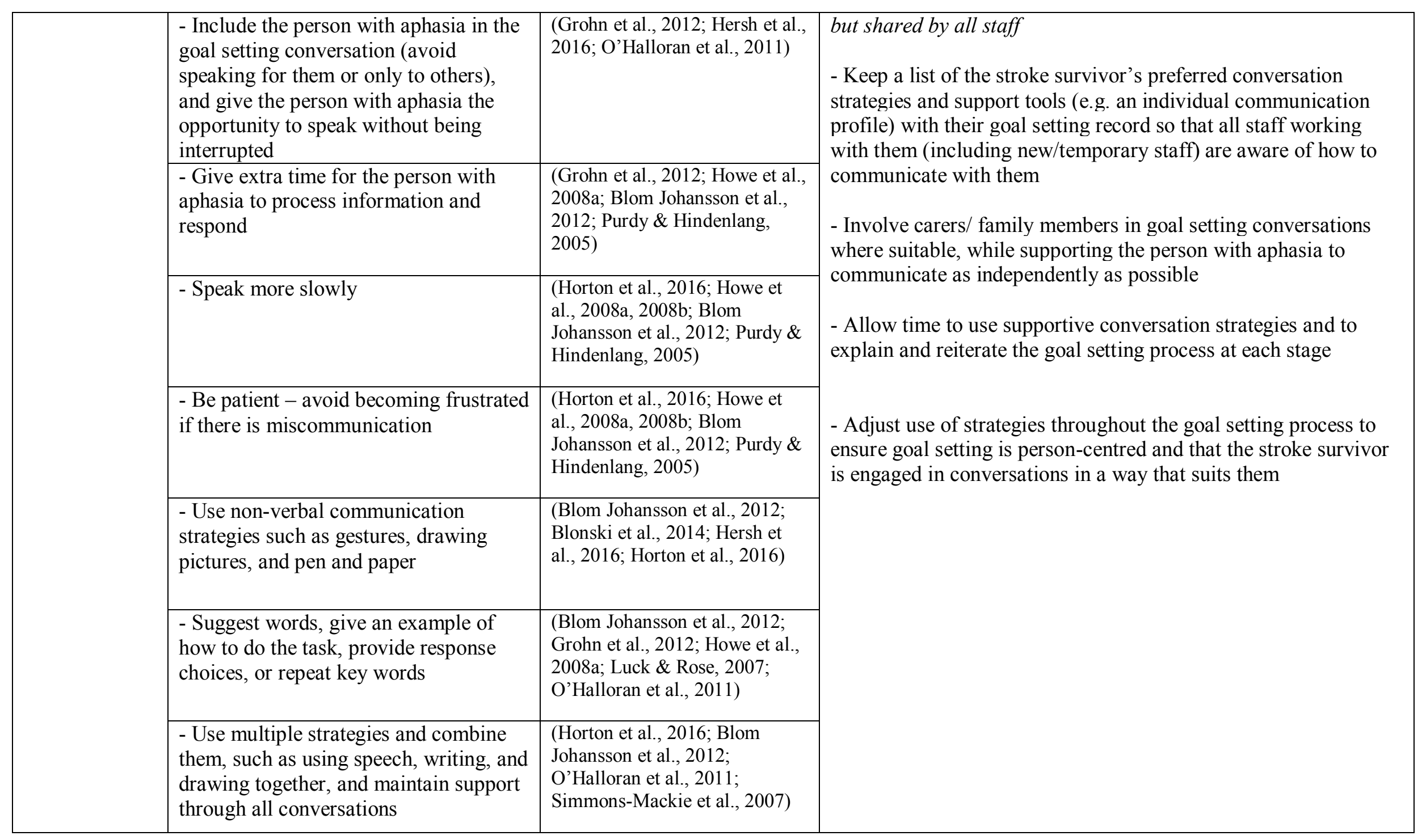




\begin{tabular}{|c|c|c|}
\hline \multirow[t]{3}{*}{ 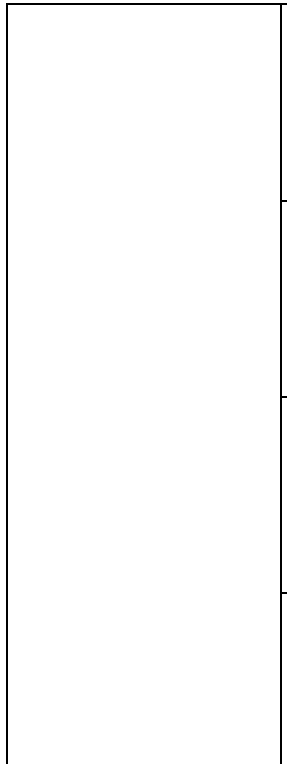 } & $\begin{array}{l}\text { - Paraphrase or rephrase what has been } \\
\text { said }\end{array}$ & $\begin{array}{l}\text { (Luck \& Rose, 2007; } \\
\text { O'Halloran et al., 2011; Purdy } \\
\text { \& Hindenlang, 2005) }\end{array}$ \\
\hline & $\begin{array}{l}\text { - Look for non-verbal cues from the } \\
\text { person with aphasia (e.g. body } \\
\text { language, facial expressions, gestures) }\end{array}$ & $\begin{array}{l}\text { (Horton et al., 2016; O’Halloran } \\
\text { et al., 2011) }\end{array}$ \\
\hline & $\begin{array}{l}\text { - Check in - check that you understand } \\
\text { each other and the conversation pace is } \\
\text { right }\end{array}$ & $\begin{array}{l}\text { (Blom Johansson et al., 2012; } \\
\text { Grohn et al., 2012; Horton et al., } \\
\text { 2016; Luck \& Rose, 2007; } \\
\text { O'Halloran et al., 2011) }\end{array}$ \\
\hline
\end{tabular}




\section{Discussion}

Our review has identified communication barriers and facilitators relevant to goal setting with stroke survivors with aphasia under the themes of communication partner and aspects of the physical environment. Our findings provide recommendations and a proposed model to support accessible goal setting. The recommendations and model can inform the development of resources and training to support stroke survivors with aphasia, their carers, and rehabilitation staff to engage collaboratively in setting and pursuing person-centred rehabilitation goals.

Our findings suggest four key implications for accessible goal setting: 1 . There is a lack of research evidence specific to accessible goal setting for stroke survivors with aphasia; our recommendations and model to support accessible goal setting provide a valuable contribution but highlight the need for further research specific to goal setting with stroke survivors with aphasia; 2. A modified physical environment must be partnered with supportive conversation strategies; 3 . Accessibility is the responsibility of all rehabilitation staff and carers; 4. Rehabilitation staff and carers require support and training to use accessible goal setting resources and conversation strategies; applying behaviour change theory may support practice change.

\section{Evidence gaps and recommendations to support accessible goal setting}

Results revealed very limited research specifically targeting accessible goal setting for stroke survivors with aphasia. Of the 33 studies included in the review, only three explicitly addressed goal setting with stroke survivors with aphasia (Bornman \& Murphy, 2006; Murphy et al., 2005; Murphy \& Boa, 2012). Murphy and Boa (2012) presented case studies demonstrating the Taking Mats ${ }^{\mathrm{TM}}$ tool with three stroke survivors with aphasia, and Murphy et al. (2005) conducted a qualitative study employing Talking Mats ${ }^{\mathrm{TM}}$ as an interview tool 
with ten participants, two of whom had post-stroke aphasia. Bornman and Murphy (2006) presented case vignettes with two participants, one of whom had post-stroke aphasia. These three articles illustrated the use of communication support tools and concrete images to provide choice, such as in Talking Mats ${ }^{\mathrm{TM}}$, to support the first goal setting stage of determining priorities and negotiating goals with stroke survivors with aphasia. However, none of the articles sought to evaluate accessible goal setting with stroke survivors with aphasia.

A more recent qualitative study by Shrubsole et al. (2019) used interviews with SLTs to explore barriers and facilitators to uptake of aphasia guideline recommendations, which include provision of accessible information and patient-centred goal setting. Findings indicated that use of accessible information and goal setting tools was variable depending on factors such as context (e.g. acute ward or inpatient rehabilitation), access to time and resources, and beliefs (e.g. about appropriateness of interventions or their own skills). While this study highlighted important implications for uptake of guidelines in SLT practice, there is a lack of comparable research exploring barriers and facilitators in multi-disciplinary stroke teams, including how non-SLT staff can approach implementation of accessible goal setting recommendations.

The lack of evidence-based accessible goal setting resources for multi-disciplinary staff is an important evidence-practice gap, given that goal setting is recommended, without exception, in stroke rehabilitation guidelines (CCRE, 2014; Heart and Stroke Foundation, 2018; Stroke Foundation, 2017; RCP, 2016), and aphasia, affecting one third of stroke survivors (Macrae \& Douglas, 2008), has been identified as a barrier to stroke survivors' participation in goal setting (Rohde et al., 2012). However, Shrubsole et al. (2019) have also identified that even where accessible tools are available in speech-language therapy practice, SLTs can experience barriers to implementing accessible goal setting, for example, due to 
time and resource constraints or believing that the tools are not appropriate or that patients are not interested.

Our evidence-based recommendations, including supportive conversation strategies and methods for adapting the physical environment, aim to inform accessible goal setting for stroke survivors with aphasia. Our recommendations align with and contribute to other recommendations and guidance related to accessibility. The Stroke Association (2012) formulated guidelines for making information accessible, designed for people with aphasia and those who work with them. The guidelines provide an overview of formatting principles gathered from research studies and focus groups. The UK NICE guidelines (2013) for stroke rehabilitation underline the importance of adapting written information and providing communication skills training to conversation partners, but detailed information about how to do this is lacking. The Australian aphasia rehabilitation best practice statements (CCRE, 2014) guide the aphasia rehabilitation pathway and recommend providing communicatively accessible information, explaining goal setting in an accessible way, and providing communication training to health professionals.

Collectively, these guidelines and our recommendations can inform accessible goal setting practice. However, all draw on evidence from heterogeneous studies, set in different contexts and addressing a range of communication interactions. Further targeted research with stroke survivors with aphasia, their families, and rehabilitation staff is required before specific recommendations are available to support accessible goal setting practice with stroke survivors with aphasia. Barriers to implementing recommendations in multi-disciplinary practice, as explored by Shrubsole et al. (2019) in SLT practice, should also be explored.

\section{Combining a modified physical environment with supportive conversation strategies}

A key component of our proposed model to support accessible goal setting practice is 
combining the modified physical environment with supportive conversation strategies. While aphasia-friendly formatting and images may make written information more accessible, it is not enough to make the whole goal setting process accessible. Equally, supportive conversation strategies alone are not enough to facilitate accessibility. Studies evaluating training programmes for rehabilitation staff employed both modified resources and supportive conversation strategies to optimise accessibility (Horton et al., 2016; Jensen et al., 2015; Simmons-Mackie et al., 2007). Therefore, it is not sufficient to provide training and support to rehabilitation staff for only communication partner training or creating an accessible physical environment - we propose that the two components must work in tandem to be successful.

\section{Sharing the responsibility for accessibility}

In any context where communication is required, communication access is the business of all communication partners (Simmons-Mackie, 2018). Stroke rehabilitation, including goal setting, is typically delivered by multi-disciplinary teams including (but not limited to) occupational therapists, physiotherapists, SLTs, and healthcare assistants (Scobbie et al., 2015). Our model to support accessible goal setting therefore proposes training and support for all rehabilitation staff, not only SLTs. It is unacceptable for stroke survivors with aphasia to only be provided with accessible communication when working with SLTs on communication goals. Accessible goal setting means equal access to the range of goals that may be relevant to each stroke survivor.

It is important that all rehabilitation staff can support stroke survivors with aphasia to communicate their personal needs, preferences, and priorities to inform person-centred goals. However, findings from this review indicate that communication accessibility may be seen as only the domain of SLTs. Other healthcare staff may feel that communication is beyond their 
discipline-specific expertise and not necessarily relevant outside of speech and language therapy (Simmons-Mackie et al., 2007). SLTs' role as communication specialists means that they are well placed to lead efforts to make goal setting accessible and provide support to other staff in the initial stages. However, the responsibility for communication accessibility must be shared among all disciplines.

\section{Training and support}

Our proposed model emphasises the need for support and training for rehabilitation teams as the foundation for accessible goal setting. Our results suggest that we cannot expect communication partners, whether staff or carers, to be intuitively skilled in making goal setting accessible. Nor can we expect that the time required will be routinely available. An updated systematic review of communication partner training in aphasia (Simmons-Mackie, Raymer, \& Cherney, 2016) recommended implementation of communication partner training for carers and health providers of people with chronic aphasia. While research evaluating training specifically for accessible goal setting in multi-disciplinary teams is currently unavailable, existing programmes for communication partner training and stroke selfmanagement can provide a starting point for future training guidelines and resources.

Simmons-Mackie et al. (2007) and Jensen et al. (2015) found positive results from implementing Supported Conversation for Adults with Aphasia (SCA $\left.{ }^{\mathrm{TM}}\right)$ techniques and tailor-made visual resources (e.g. image cards) with healthcare staff in hospital settings. While $\mathrm{SCA}^{\mathrm{TM}}$ itself requires specialist training, these studies demonstrate how staff training can be delivered using methods such as workshops and training aphasia team leaders.

Better Conversations with Aphasia is an e-learning programme designed to educate SLTs, people with aphasia, and their families about conversation therapy (Beeke et al., 2013). Although aimed at practicing or training SLTs; it provides an example of how 
communication training can be delivered online to potentially reach more people than inperson training (Beeke et al., 2013).

The Bridges Self-Management Programme was developed to include accessible workbooks, and therapists or teams can undertake training workshops that cover awareness of communication differences (Jones et al., 2016; McKenna et al., 2013). While the emphasis of this training is on facilitating self-management rather than learning supported communication techniques for goal setting, it includes a person-centred approach and practical tools for delivering Bridges in clinical practice to people with a range of communication difficulties, including aphasia (Jones et al., 2016).

Carers are also key communication partners and may wish to be involved in goal setting (Howe et al., 2012). Communication partner training and resources such as the Stroke Association accessible information guidelines can be made available to support carers who want to be involved in goal setting. However, there does not appear to be training that specifically targets supporting communication partner training for carers in the context of goal setting. While not all stroke survivors with aphasia may have carers directly involved in their rehabilitation, relationships and social circles are identified as a key part of recovery goals (Worrall et al., 2011). Accessible goal setting training could include helping carers to apply supportive conversation strategies and use accessible resources. In this way, the responsibility for making goal setting accessible can be led by staff but shared with carers.

The application of behaviour change theory (e.g. Michie, van Stralen, \& West, 2011) could inform implementation of accessible goal setting practice with rehabilitation staff. For example, Shrubsole, Worrall, Powers, and O'Connor (2018) used Michie et al.'s (2011) behaviour change wheel to inform implementation of a behaviour change intervention with SLTs, targeted at improving information provision and goal setting practice. By addressing relevant facilitators such as environmental restructuring (e.g. providing educational 
resources) and modelling (e.g. role playing conversation with people with aphasia), the intervention proved to be an acceptable and feasible method for facilitating practice change (Shrubsole et al., 2018).

\section{Limitations}

Available literature covered varied topics across communication accessibility for aphasia, and there was a lack of literature specifically addressing accessible goal setting for stroke survivors with aphasia. Therefore, findings were compiled from a range of communication topics in different contexts in the literature and applied to goal setting theoretically. Further, including "stroke" as a required search term and searching abstracts only may have excluded articles that included people with aphasia as part of wider participant groups or did not focus on stroke as an aphasia aetiology.

\section{Conclusions}

Our review highlights the need for service-level training and support so that rehabilitation staff can apply supportive conversation strategies and create an accessible physical environment for goal setting with stroke survivors with aphasia. We have proposed a model to support accessible goal setting. Further, our recommendations, targeted to multidisciplinary teams, are based on evidence supporting the use of conversation strategies and a modified physical environment. More research is required to develop and evaluate accessible goal setting resources, training, and support for rehabilitation staff and carers so that guidelines are based on strong evidence. Further research is also required to investigate relationships between the key components proposed in this model and how each could be prioritised to optimise implementation of an accessible goal setting process. Given the prevalence of aphasia among stroke survivors, improving accessibility in goal setting and in 
all aspects of the rehabilitation pathway is essential for all stroke survivors to have equal access to rehabilitation opportunities.

Acknowledgements, avoiding identifying any of the authors prior to peer review

EB was supported by a Glasgow Caledonian University PhD Studentship; LS was supported by a Stroke Association Clinical Lectureship (TSA LECT 2016/02); MB and NMAHP-RU were supported by the Chief Scientist Office, Scottish Government Health and Social Care Directorate. 


\section{References}

Arksey, H., \& O’Malley, L. (2005). Scoping studies: Towards a methodological framework. International Journal of Social Research Methodology, 8(1), 19-32.

Ashton, C., Aziz, N. A., Barwood, C., French, R., Savina, E., \& Worrall, L. (2008). Communicatively accessible public transport for people with aphasia: A pilot study. Aphasiology, 22(3), 305-320. https://doi.org/http://dx.doi.org/10.1080/02687030701382841

Barnes, S., \& Ferguson, A. (2015). Conversation partner responses to problematic talk produced by people with aphasia: some alternatives to initiating, completing, or pursuing repair. Aphasiology, 29(3), 315-336. https://doi.org/10.1080/02687038.2013.874547

Beeke, S., Sirman, N., Beckley, F., Maxim, J., Edwards, S., Swinburn, K., \& Best, W. (2013). Better Conversations with Apahsia: an e-learning resource. https://extend.ucl.ac.uk

Blom Johansson, M., Carlsson, M., Östberg, P., \& Sonnander, K. (2012). Communication changes and SLP services according to significant others of persons with aphasia. Aphasiology, 26(8), 1005-1028. https://doi.org/10.1080/02687038.2012.671927

Blom Johansson, M., Carlsson, M., Östberg, P., \& Sonnander, K. (2013). A multiple-case study of a family-oriented intervention practice in the early rehabilitation phase of persons with aphasia. Aphasiology, 27(2), 201-226. https://doi.org/10.1080/02687038.2012.744808

Blonski, D. C., Covert, M., Gauthier, R., Monas, A., Murray, D., O’Brien, K. K., Mendelson, A. D., \& Huijbregts, M. (2014). Barriers to and facilitators of access and participation in community-based exercise programmes from the perspective of adults with post-stroke aphasia. Physiotherapy Canada, 66(4), 367-375. https://doi.org/10.3138/ptc.2013-70

Bornman, J., \& Murphy, J. (2006). Using the ICF in goal setting: Clinical application using Talking Mats ${ }^{\circledR}$. Disability and Rehabilitation: Assistive Technology, 1(3), 145-154. 
https://doi.org/10.1080/17483100612331392745

Brandenburg, C., Worrall, L., Copland, D., \& Rodriguez, A. D. (2017). Barriers and facilitators to using the CommFit ${ }^{\mathrm{TM}}$ smart phone app to measure talk time for people with aphasia. Aphasiology, 31(8), 901-927. https://search.proquest.com/docview/2001079598?accountid=15977

Braun, V., \& Clarke, V. (2006). Using thematic analysis in psychology. Qualitative Research in Psychology, 3(2), 77-101.

Clinical Centre for Research Excellence in Aphasia Rehabilitation. (2014). Aphasia rehabilitation best practice statements: Comprehensive supplement to the Australian aphasia rehabilitation pathway. http://www.aphasiapathway.com.au/fluxcontent/aarp/pdf/2014-COMPREHENSIVE-FINAL-01-10-2014-1.pdf

Coulter, A., Entwistle, V. A., Eccles, A., Ryan, S., Shepperd, S., \& Perera, R. (2015). Personalised care planning for adults with chronic or long-term health conditions. Cochrane Database of Systematic Reviews. https://doi.org/10.1002/14651858.CD010523.pub2

Croteau, C., \& Le Dorze, G. (2006). Overprotection, “speaking for", and conversational participation: A study of couples with aphasia. Aphasiology, 20(2-4), 327-336. https://doi.org/10.1080/02687030500475051

Croteau, C., Vychytil, A.-M., Larfeuil, C., \& Le Dorze, G. (2004). “Speaking for” behaviours in spouses of people with aphasia: A descriptive study of six couples in an interview situation. Aphasiology, 18(4), 291-312. https://doi.org/http://dx.doi.org/10.1080/02687030344000616

Dalemans, R. J. P., De Witte, L. P., Wade, D. T., \& Van den Heuvel, W. J. A. (2008). A description of social participation in working-age persons with aphasia: A review of the literature. Aphasiology, 22(10), 1071-1091. https://doi.org/http://dx.doi.org/10.1080/02687030701632179 
Dietz, A., Hux, K., McKelvey, M. L., Beukelman, D. R., \& Weissling, K. (2009). Reading comprehension by people with chronic aphasia: A comparison of three levels of visuographic contextual support. Aphasiology, 23(7-8), 1053-1064. https://doi.org/10.1080/02687030802635832

Dietz, A., Thiessen, A., Griffith, J., Peterson, A., Sawyer, E., \& McKelvey, M. (2013). The renegotiation of social roles in chronic aphasia: Finding a voice through AAC. Aphasiology, 27(3), 309-325. https://doi.org/http://dx.doi.org/10.1080/02687038.2012.725241

Dixon-Woods, M., Agarwal, S., Jones, D., Young, B., \& Sutton, A. (2005). Synthesising qualitative and quantitative evidence: A review of possible methods. Journal of Health Services Research \& Policy, 10(1), 45-53.

Eames, S., McKenna, K., Worrall, L., \& Read, S. (2003). Grand rounds. The suitability of written education materials for stroke survivors and their carers. Topics in Stroke Rehabilitation, 10(3), 70-83. http://search.ebscohost.com/login.aspx?direct=true $\& d b=\operatorname{cin} 20 \& A N=106746018 \&$ site $=e$ host-live\&scope $=$ site

Egan, J., Worrall, L., \& Oxenham, D. (2004). Accessible Internet training package helps people with aphasia cross the digital divide. Aphasiology, 18(3), 265-280. https://doi.org/10.1080/02687030344000562

Ferrari, R. (2015). Writing narrative style literature reviews. Medical Writing, 24(4), 230235.

Grant, M., \& Booth, A. (2009). A typology of reviews: An analysis of 14 review types and associated methodologies. Health Information \& Libraries Journal, 26(2), 91-108.

Greenhalgh, T., Thorne, S., \& Malterud, K. (2018). Time to challenge the spurious hierarchy of systematic over narrative reviews? European Journal of Clinical Investigation, 48(6), e12931. https://doi.org/10.1111/eci.12931 
Greig, C.-A., Harper, R., Hirst, T., Howe, T., \& Davidson, B. (2008). Barriers and facilitators to mobile phone use for people with aphasia. Topics in Stroke Rehabilitation, 15(4), 307-324. https://doi.org/10.1310/tsr1504-307

Grohn, B., Worrall, L. E., Simmons-Mackie, N., \& Brown, K. (2012). The first 3-months post-stroke: What facilitates successfully living with aphasia? International Journal of Speech-Language Pathology, 14(4), 390-400. https://doi.org/http://dx.doi.org/10.3109/17549507.2012.692813

Heart and Stroke Foundation (2018). Canadian Stroke Best Practice Recommendations, 6th Edition.

Hersh, D., Godecke, E., Armstrong, E., Ciccone, N., \& Bernhardt, J. (2016). "Ward talk": Nurses' interaction with people with and without aphasia in the very early period poststroke. Aphasiology, 30(5), 609-628. https://doi.org/http://dx.doi.org/10.1080/02687038.2014.933520

Hersh, D., Sherratt, S., Howe, T., Worrall, L., Davidson, B., \& Ferguson, A. (2012). An analysis of the "goal" in aphasia rehabilitation. Aphasiology, 26(8), 971-984. https://doi.org/http://dx.doi.org/10.1080/02687038.2012.684339

Hilton, R., Leenhouts, S., Webster, J., \& Morris, J. (2014). Information, support and training needs of relatives of people with aphasia: Evidence from the literature. Aphasiology, 28(7), 797-822. https://doi.org/http://dx.doi.org/10.1080/02687038.2014.906562

Hoffmann, T., \& McKenna, K. (2006). Analysis of stroke patients' and carers' reading ability and the content and design of written materials: recommendations for improving written stroke information. Patient Education and Counseling, 60(3), 286-293. https://doi.org/10.1016/j.pec.2005.06.020

Holliday, R. C., Ballinger, C., \& Playford, E. D. (2007). Goal setting in neurological rehabilitation: Patients' perspectives. Disability and Rehabilitation, 29(5), 389-394. https://doi.org/10.1080/09638280600841117 
Horton, S., Lane, K., \& Shiggins, C. (2016). Supporting communication for people with aphasia in stroke rehabilitation: Transfer of training in a multidisciplinary stroke team. Aphasiology, 30(5), 629-656.

https://doi.org/http://dx.doi.org/10.1080/02687038.2014.1000819

Howe, T., Davidson, B., Worrall, L., Hersh, D., Ferguson, A., Sherratt, S., \& Gilbert, J. (2012). 'You needed to rehab ... families as well': Family members' own goals for aphasia rehabilitation. International Journal of Language \& Communication Disorders, 47(5), 511-521. https://doi.org/http://dx.doi.org/10.1111/j.1460-6984.2012.00159.x

Howe, T. J., Worall, L. E., \& Hickson, L. M. H. (2004). What is an aphasia-friendly environment? Aphasiology, 18(11), 1015-1037. https://doi.org/10.1080/02687030444000499

Howe, T. J., Worrall, L. E., \& Hickson, L. M. H. (2008a). Interviews with people with aphasia: Environmental factors that influence their community participation. Aphasiology, 22(10), 1-29. https://doi.org/http://dx.doi.org/10.1080/02687030701640941

Howe, T. J., Worrall, L. E., \& Hickson, L. M. H. (2008b). Observing people with aphasia: Environmental factors that influence their community participation. Aphasiology, 22(6), 618-643. https://doi.org/10.1080/02687030701536024

Jensen, L. R., Løvholt, A. P., Sørensen, I. R., Blüdnikow, A. M., Iversen, H. K., Hougaard, A., Mathiesen, L. L., \& Forchhammer, H. B. (2015). Implementation of supported conversation for communication between nursing staff and in-hospital patients with aphasia. Aphasiology, 29(1), 57-80. https://doi.org/10.1080/02687038.2014.955708

Johansson, M. B., Carlsson, M., \& Sonnander, K. (2012). Communication difficulties and the use of communication strategies: from the perspective of individuals with aphasia. International Journal of Language \& Communication Disorders, 47(2), 144-155. https://doi.org/10.1111/j.1460-6984.2011.00089.x

Jones, F., Postges, H., \& Brimicombe, L. (2016). Building Bridges between healthcare 
professionals, patients and families: A coproduced and integrated approach to selfmanagement support in stroke. NeuroRehabilitation, 39(4), 471-480.

https://doi.org/10.3233/NRE-161379

Levack, W., Weatherall, M., Hay-Smith, E., Dean, S., Mcpherson, K., \& Siegert, R. (2015). Goal setting and strategies to enhance goal pursuit for adults with acquired disability participating in rehabilitation. The Cochrane Database of Systematic Reviews.

Luck, A. M., \& Rose, M. L. (2007). Interviewing people with aphasia: Insights into method adjustments from a pilot study. Aphasiology, 21(2), 208-224. https://doi.org/http://dx.doi.org/10.1080/02687030601065470

Macrae, M., \& Douglas, J. M. (2008). Communication outcome 12 months following lefthemisphere stroke in the elderly. Brain Impairment, 9(2), 170-178.

Mays, N., Pope, C., \& Popay, J. (2005). Systematically reviewing qualitative and quantitative evidence to inform management and policy-making in the health field. Journal of Health Services Research \& Policy, 10, 6-20.

McKenna, S., Jones, F., Glenfield, P., \& Lennon, S. (2013). Bridges self-management program for people with stroke in the community: A feasibility randomized controlled trial. International Journal of Stroke, 10, 697-704.

Michie, S., van Stralen, M. M., \& West, R. (2011). The behaviour change wheel: A new method for characterising and designing behaviour change interventions. Implementation Science, 6(1), 42. https://doi.org/10.1186/1748-5908-6-42

Murphy, J, Tester, S., Hubbard, G., Downs, M., \& MacDonald, C. (2005). Enabling frail older people with a communication difficulty to express their views: the use of Talking Mats as an interview tool. Health \& Social Care in the Community, 13(2), 95-107. http://search.ebscohost.com/login.aspx?direct=true \&db=cin20\&AN=106608962\&site=e host-live \&scope $=$ site

Murphy, Joan, \& Boa, S. (2012). Using the WHO-ICF with Talking Mats to Enable Adults 
with Long-term Communication Difficulties to Participate in Goal Setting.

Augmentative and Alternative Communication, 28(1), 52-60.

https://doi.org/10.3109/07434618.2011.653828

National Institute for Health and Care Excellence. (2013). Stroke rehabilitation: Long term rehabilitation after stroke (Clinical Guideline 162).

https://www.nice.org.uk/guidance/cg162/evidence/full-guideline-pdf-190076509

O’Halloran, R., Worrall, L., \& Hickson, L. (2011). Environmental factors that influence communication between patients and their healthcare providers in acute hospital stroke units: An observational study. International Journal of Language \& Communication Disorders, 46(1), 30-47. https://search.proquest.com/docview/1230617125?accountid=15977

Physicians, R. C. of. (2016). National clinical guideline for stroke (fifth edition). https://www.strokeaudit.org/SupportFiles/Documents/Guidelines/2016-NationalClinical-Guideline-for-Stroke-5t-(1).aspx

Plant, S., Tyson, S., Kirk, S., \& Parsons, J. (2016). What are the barriers and facilitators to goal-setting during rehabilitation for stroke and other acquired brain injuries? A systematic review and meta-synthesis. Clinical Rehabilitation, 30(9), 921-930.

Pluye, P., Robert, E., Cargo, M., Bartlett, G., O’Cathain, A., Griffiths, F., Boardman, F., Gagnon, M. P., \& Rousseau, M. C. (2018, February). Proposal: A mixed methods appraisal tool for systematic mixed studies reviews. Department of Family Medicine, McGill University, Montreal, Canada. http://mixedmethodsappraisaltoolpublic.pbworks.com

Prescott, S., Fleming, J., \& Doig, E. (2015). Goal setting approaches and principles used in rehabilitation for people with acquired brain injury: A systematic scoping review. Brain Injury, 1515-1529.

Purdy, M., \& Hindenlang, J. (2005). Educating and training caregivers of persons with aphasia. Aphasiology, 19(3-5), 377-388. 
https://doi.org/http://dx.doi.org/10.1080/02687030444000822

Rohde, A., Townley-O’Neill, K., Trendall, K., Worrall, L., \& Cornwell, P. (2012). A comparison of client and therapist goals for people with aphasia: A qualitative exploratory study. Aphasiology, 26(10), 1298-1315.

Rose, T. A., Worrall, L. E., Hickson, L. M., \& Hoffmann, T. C. (2011a). Aphasia friendly written health information: Content and design characteristics. International Journal of Speech-Language Pathology, 13(4), 335-347. https://doi.org/http://dx.doi.org/10.3109/17549507.2011.560396

Rose, T. A., Worrall, L. E., Hickson, L. M., \& Hoffmann, T. C. (2011b). Exploring the use of graphics in written health information for people with aphasia. Aphasiology, 25(12), 1579-1599. https://doi.org/10.1080/02687038.2011.626845

Rose, T. A., Worrall, L. E., Hickson, L. M., \& Hoffmann, T. C. (2012). Guiding principles for printed education materials: Design preferences of people with aphasia. International Journal of Speech-Language Pathology, 14(1), 11-23. https://doi.org/http://dx.doi.org/10.3109/17549507.2011.631583

Rose, T., Worrall, L., Hickson, L., \& Hoffmann, T. (2010). Do people with aphasia want written stroke and aphasia information? A verbal survey exploring preferences for when and how to provide stroke and aphasia information. Topics in Stroke Rehabilitation, 17(2), 79-98. https://doi.org/http://dx.doi.org/10.1310/tsr1702-79

Rose, T., Worrall, L., \& McKenna, K. (2003). The effectiveness of aphasia-friendly principles for printed health education materials for people with aphasia following stroke. Aphasiology, 17(10), 947-963. https://doi.org/10.1080/02687030344000319

Rosewilliam, S., Roskell, C., \& Pandyan, A. (2011). A systematic review and synthesis of the quantitative and qualitative evidence behind patient-centred goal setting in stroke rehabilitation. Clinical Rehabilitation, 25(6), 501-514.

Scobbie, L., Dixon, D., \& Wyke, S. (2011). Goal setting and action planning in the 
rehabilitation setting: Development of a theoretically informed practice framework. Clinical Rehabilitation, 25(5), 468-482.

Scobbie, L., Duncan, E., Brady, M., \& Wyke, S. (2015). Goal setting practice in services delivering community-based stroke rehabilitation: A United Kingdom (UK) wide survey. Disability and Rehabilitation, 37(14), 1291-1298.

Scobbie, L., McLean, D., Dixon, D., Duncan, E., \& Wyke, S. (2013). Implementing a framework for goal setting in community based stroke rehabilitation: A process evaluation. BMC Health Services Research, 13(190).

Shrubsole, K., Worrall, L., Power, E., \& O’Connor, D. A. (2018). The Acute Aphasia IMplementation Study (AAIMS): a pilot cluster randomized controlled trial. International Journal of Language \& Communication Disorders, 53(5), 1021-1056. https://doi.org/10.1111/1460-6984.12419

Shrubsole, K., Worrall, L., Power, E., \& O’Connor, D. A. (2019). Barriers and facilitators to meeting aphasia guideline recommendations: what factors influence speech pathologists' practice? Disability and Rehabilitation, 41(13), 1596-1607. https://doi.org/10.1080/09638288.2018.1432706

Simmons-Mackie, N. N., Kagan, A., O’Neill Christie, C., Huijbregts, M., McEwen, S., \& Willems, J. (2007). Communicative access and decision making for people with aphasia: Implementing sustainable healthcare systems change. Aphasiology, 21(1), 39-66.

Simmons-Mackie, N, \& Kagan, A. (2007). Application of the ICF in aphasia. Seminars in Speech \& Language, 28(4), 244-253.

http://search.ebscohost.com/login.aspx?direct=true \&db=cin20\&AN=105830999\&site=e host-live \&scope $=$ site

Simmons-Mackie, Nina. (2018). Communication partner training in aphasia: reflections on communication accommodation theory. Aphasiology, 1-10. https://doi.org/10.1080/02687038.2018.1428282 
Simmons-Mackie, Nina, Raymer, A., \& Cherney, L. R. (2016). Communication Partner Training in Aphasia: An Updated Systematic Review. Archives of Physical Medicine and Rehabilitation, 97(12), 2202-2221.e8. https://doi.org/10.1016/j.apmr.2016.03.023

Snyder, H., \& Engström, J. (2016). The antecedents, forms and consequences of patient involvement: A narrative review of the literature. International Journal of Nursing Studies, 53, 351-378.

Stroke Association (2012). Accessible information guidelines: Making information accessible for people with aphasia.

Stroke Foundation (2017). Clinical guidelines for stroke management (Australia). https://informme.org.au/en/Guidelines/Clinical-Guidelines-for-Stroke-Management2017

Sugavanam, T., Mead, G., Bulley, C., Donaghy, M., Wijck, V., \& F. (2013). The effects and experiences of goal setting in stroke rehabilitation a systematic review. Disability and Rehabilitation, 35(3), 177-190.

Van De Weyer, R. C., Ballinger, C., \& Playford, E. D. (2010). Goal setting in neurological rehabilitation: staff perspectives. Disability and Rehabilitation, 32(17), 1419-1427. https://doi.org/10.3109/09638280903574345

Worrall, L, Rose, T., Howe, T., Brennan, A., Egan, J., Oxenham, D., \& Mckenna, K. (2005). Access to written information for people with aphasia. Aphasiology, 19(10-11), 923929.

Worrall, Linda, Rose, T., Howe, T., McKenna, K., \& Hickson, L. (2007). Developing an evidence-base for accessibility for people with aphasia. Aphasiology, 21(1), 124-136. https://doi.org/10.1080/02687030600798352

Worrall, Linda, Sherratt, S., Rogers, P., Howe, T., Hersh, D., Ferguson, A., \& Davidson, B. (2011). What people with aphasia want: Their goals according to the ICF. Aphasiology, 25(3), 309-322. https://doi.org/10.1080/02687038.2010.508530 


\section{Appendices}

Appendix A: Search terms represented and CINAHL search strategy

Keywords

- stroke

- aphasia/dysphasia/aphasic/dysphasic/language impairment/communication impairment/communication disability

- accessibility/facilitator/support/modify/adapt/assist/aphasia-friendly

- barrier/difficulty/challenge/ limitation

CINAHL search string

1. AB stroke

2. $A B$ aphasi* $O R A B$ dysphasi* $A B$ language impairment* $O R A B$ communication impairment* $\mathrm{OR} \mathrm{AB}$ communication disabilit*)

3. 1 AND 2

4. $A B$ access* $O R$ AB facilitat* $O R$ support* $O R A B$ modif* $O R A B$ adapt* $O R$ assist* $\mathrm{OR} A B$ friendly

5. AB barrier* OR AB difficult* OR AB challeng* OR AB limit*

6. 4 OR 5

7. 3 AND 6

$\mathrm{AB}=$ abstract $^{*}=$ truncation (e.g. access ${ }^{*}$ covers access, accessible, accessibility, etc.) 


\section{Appendix B: Inclusion screening questions}

\section{Inclusion screening questions}

1. Is the article a peer-reviewed joumal publication?

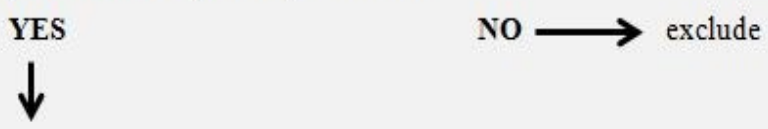

2. Was the article published in English between 2003 and 2018 ?

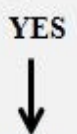

NO $\longrightarrow$ exclude

3. Is the article a qualitative/ quantitative/mixed methods study, or a literature review or multiple case report?

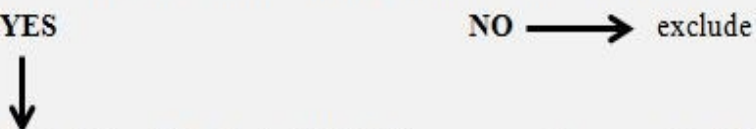

4. Is the article about adults with aphasia OR staff or carers who support adults with aphasia?

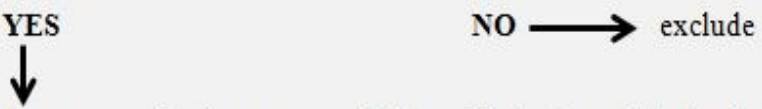

5. Is the article about communication partner skills and behaviours OR the characteristics of physical resources?

YES

No $\longrightarrow$ exclude 


\section{Appendix C: Data extraction table template}

(1) Communication partner skills and behaviours (e.g. training programmes, techniques, observations/descriptions of behaviours that impact on communication)

(2) Physical environment

a. Written information (e.g. information sheets, timetables, signs)

b. Pictures and images (e.g. graphics on maps/signs and other information sources)

c. Communication support tools (e.g. picture cards, technology)

d. Place and structure (e.g. procedures, noise, room set-up or facilities)

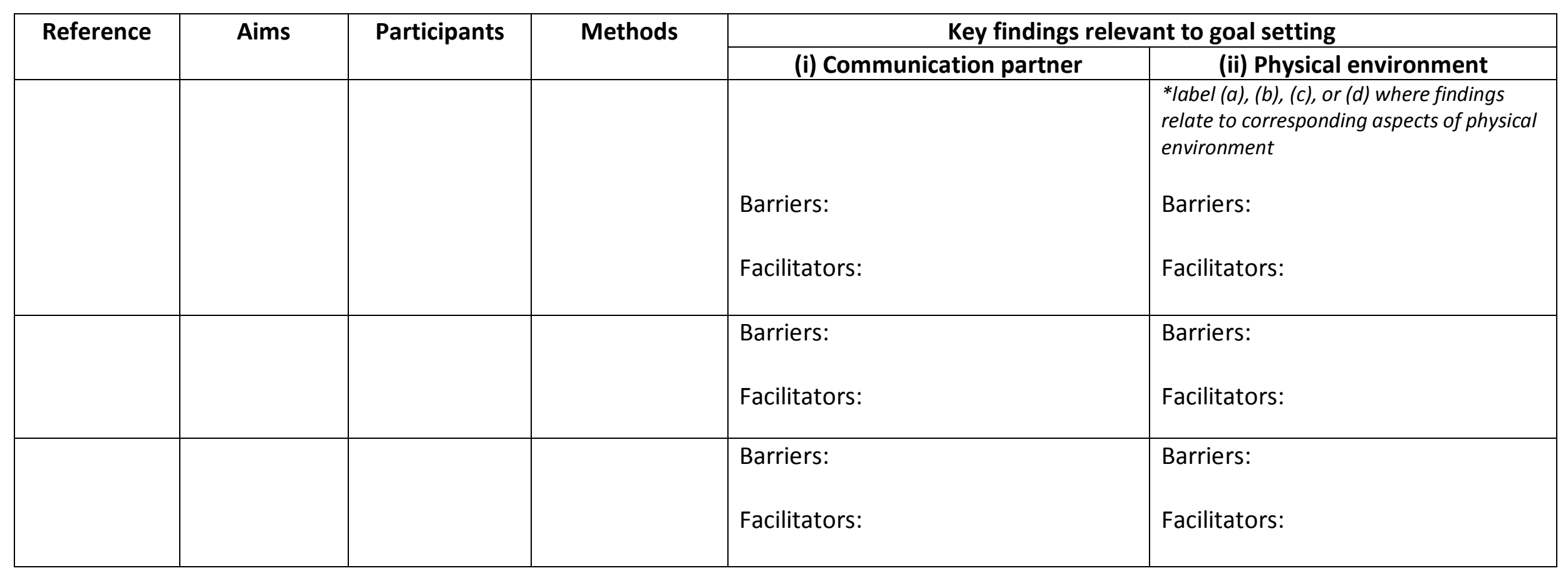




\section{Appendix D: Table of included studies and MMAT quality scores}

\section{Included studies}

Ashton, C., Aziz, N. A., Barwood, C., French, R., Savina, E., \& Worrall, L. (2008). Communicatively accessible public transport for people with aphasia: A pilot study. Aphasiology, 22(3), 305-320.

Barnes, S., \& Ferguson, A. (2015). Conversation partner responses to problematic talk produced by people with aphasia: some alternatives to initiating, completing, or pursuing repair. Aphasiology, 29(3), 315-336.

Blom Johansson, M., Carlsson, M., Östberg, P., \& Sonnander, K. (2012). Communication changes and SLP services according to significant others of persons with aphasia. Aphasiology, 26(8), 1005-1028.

Blom Johansson, M., Carlsson, M., Östberg, P., \& Sonnander, K. (2013). A multiple-case study of a family-oriented intervention practice in the early rehabilitation phase of persons with aphasia. Aphasiology, 27(2), 201-226.

Blom Johansson, M., Carlsson, M., \& Sonnander, K. (2012). Communication difficulties and the use of communication strategies: from the perspective of individuals with aphasia. International Journal of Language \& Communication Disorders, 47(2), 144-155.

Blonski, D. C., Covert, M., Gauthier, R., Monas, A., Murray, D., O’Brien, K. K., Huijbregts, M. (2014). Barriers to and facilitators of access and participation in community-based exercise programmes from the perspective of adults with post-stroke aphasia. Physiotherapy Canada, 66(4), 367-375.

Bornman, J., \& Murphy, J. (2006). Using the ICF in goal setting: Clinical application using Talking Mats ${ }^{\circledR}$. Disability and Rehabilitation: Assistive Technology, 1(3), 145-154.

Brandenburg, C., Worrall, L., Copland, D., \& Rodriguez, A. D. (2017). Barriers and facilitators to using the CommFit ${ }^{\text {TM }}$ smart

MMAT score

$75 \%$ 


\begin{tabular}{|c|c|}
\hline phone app to measure talk time for people with aphasia. Aphasiology, 31(8), 901-927. & \\
\hline $\begin{array}{l}\text { Croteau, C., \& Le Dorze, G. (2006). Overprotection, "speaking for", and conversational participation: A study of couples with } \\
\text { aphasia. Aphasiology, 20(2-4), 327-336. } \\
\text { Croteau, C., Vychytil, A.-M., Larfeuil, C., \& Le Dorze, G. (2004). "Speaking for" behaviours in spouses of people with aphasia: A } \\
\text { descriptive study of six couples in an interview situation. Aphasiology, 18(4), 291-312. }\end{array}$ & $75 \%$ \\
\hline $\begin{array}{l}\text { Dalemans, R. J. P., De Witte, L. P., Wade, D. T., \& Van den Heuvel, W. J. A. (2008). A description of social participation in } \\
\text { working-age persons with aphasia: A review of the literature. Aphasiology, 22(10), 1071-1091. }\end{array}$ & $50 \%$ \\
\hline $\begin{array}{l}\text { Dietz, A., Hux, K., McKelvey, M. L., Beukelman, D. R., \& Weissling, K. (2009). Reading comprehension by people with chronic } \\
\text { aphasia: A comparison of three levels of visuographic contextual support. Aphasiology, 23(7-8), 1053-1064. }\end{array}$ & $75 \%$ \\
\hline $\begin{array}{l}\text { Dietz, A., Thiessen, A., Griffith, J., Peterson, A., Sawyer, E., \& McKelvey, M. (2013). The renegotiation of social roles in chronic } \\
\text { aphasia: Finding a voice through AAC. Aphasiology, 27(3), 309-325. }\end{array}$ & $100 \%$ \\
\hline $\begin{array}{l}\text { Eames, S., McKenna, K., Worrall, L., \& Read, S. (2003). Grand rounds. The suitability of written education materials for stroke } \\
\text { survivors and their carers. Topics in Stroke Rehabilitation, 10(3), 70-83. }\end{array}$ & $100 \%$ \\
\hline $\begin{array}{l}\text { Egan, J., Worrall, L., \& Oxenham, D. (2004). Accessible Internet training package helps people with aphasia cross the digital } \\
\text { divide. Aphasiology, 18(3), 265-280. }\end{array}$ & $100 \%$ \\
\hline $\begin{array}{l}\text { Greig, C.-A., Harper, R., Hirst, T., Howe, T., \& Davidson, B. (2008). Barriers and facilitators to mobile phone use for people } \\
\text { with aphasia. Topics in Stroke Rehabilitation, 15(4), 307-324. }\end{array}$ & $75 \%$ \\
\hline $\begin{array}{l}\text { Grohn, B., Worrall, L., Simmons-Mackie, N., \& Hudson, K. (2014). Living successfully with aphasia during the first year post- } \\
\text { stroke: A longitudinal qualitative study. Aphasiology, 28(12), 1405-1425. }\end{array}$ & $100 \%$ \\
\hline
\end{tabular}


Hersh, D., Godecke, E., Armstrong, E., Ciccone, N., \& Bernhardt, J. (2016). "Ward talk": Nurses' interaction with people with and without aphasia in the very early period poststroke. Aphasiology, 30(5), 609-628.

Hilton, R., Leenhouts, S., Webster, J., \& Morris, J. (2014). Information, support and training needs of relatives of people with aphasia: Evidence from the literature. Aphasiology, 28(7), 797-822.

Hoffmann, T., \& McKenna, K. (2006). Analysis of stroke patients' and carers' reading ability and the content and design of written materials: recommendations for improving written stroke information. Patient Education and Counseling, 60(3), 286293.

Horton, S., Lane, K., \& Shiggins, C. (2016). Supporting communication for people with aphasia in stroke rehabilitation: Transfer of training in a multidisciplinary stroke team. Aphasiology, 30(5), 629-656.

Howe, T. J., Worrall, L. E., \& Hickson, L. M. H. (2008a). Interviews with people with aphasia: Environmental factors that influence their community participation. Aphasiology, 22(10), 1-29.

Howe, T. J., Worrall, L. E., \& Hickson, L. M. H. (2008b). Observing people with aphasia: Environmental factors that influence their community participation. Aphasiology, 22(6), 618-643.

Jensen, L. R., Løvholt, A. P., Sørensen, I. R., Blüdnikow, A. M., Iversen, H. K., Hougaard, A., ... Forchhammer, H. B. (2015). Implementation of supported conversation for communication between nursing staff and in-hospital patients with aphasia. Aphasiology, 29(1), 57-80.

Luck, A. M., \& Rose, M. L. (2007). Interviewing people with aphasia: Insights into method adjustments from a pilot study. Aphasiology, 21(2), 208-224.

Murphy, J., \& Boa, S. (2012). Using the WHO-ICF with Talking Mats to Enable Adults with Long-term Communication 


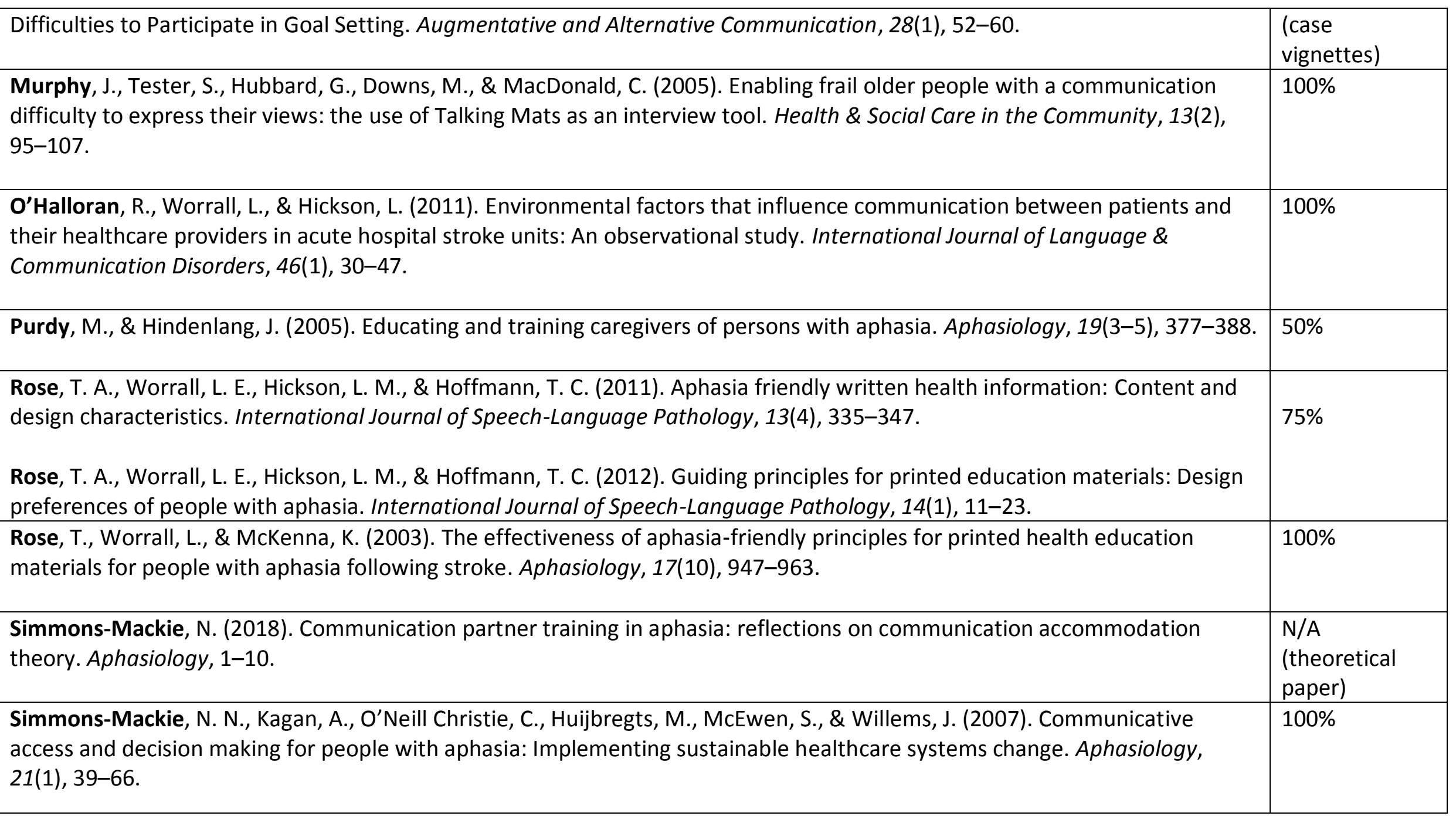

